\title{
Application of nanodiagnostics and nanotherapy to CNS diseases
}

\author{
Weiyuan Zhang ${ }^{1}$, Wenyue Wang ${ }^{2}$, David X Yu², Zhicheng Xiao**,2 \& Zhiyong He*,1,2 \\ ${ }^{1}$ Yunnan Key Laboratory of Stem Cell \& Regenerative Medicine, Institute of Molecular \& Clinical Medicine, Kunming Medical \\ University, Kunming 650500, PR China \\ ${ }^{2}$ Department of Anatomy \& Developmental Biology, Monash University, Clayton, 3800 Clayton, Melbourne 3800, Australia \\ *Author for correspondence: Tel.: +86 1591241 3854; Fax: +86 8716592 2700; zhiyong.he2@monash.edu \\ **Author for correspondence: zhicheng.xiao@monash.edu
}

\begin{abstract}
Alzheimer's disease, Parkinson's disease and stroke are the most common CNS diseases, all characterized by progressive cellular dysfunction and death in specific areas of the nervous system. Therapeutic development for these diseases has lagged behind other disease areas due to difficulties in early diagnosis, long disease courses and drug delivery challenges, not least due to the blood-brain barrier. Over recent decades, nanotechnology has been explored as a potential tool for the diagnosis, treatment and monitoring of CNS diseases. In this review, we describe the application of nanotechnology to common CNS diseases, highlighting disease pathogenesis and the underlying mechanisms and promising functional outcomes that make nanomaterials ideal candidates for early diagnosis and therapy. Moreover, we discuss the limitations of nanotechnology, and possible solutions.
\end{abstract}

First draft submitted: 9 May 2018; Accepted for publication: 16 July 2018; Published online: 8 August 2018

Keywords: blood-brain barrier $\bullet$ nanotechnology $\bullet$ neurodegenerative disease $\bullet$ neuroinflammation $\bullet$ theranostics

CNS diseases are a group of neurological disorders that affect the neuronal structure and function of the brain or spinal cord. CNS diseases, especially Alzheimer's disease (AD) [1], Parkinson's disease (PD) [2] and stroke [3], have become a significant healthcare challenge, not least with a rapidly aging population. Although advances have been made in understanding the pathogenesis of CNS diseases, early diagnosis and treatment remain elusive and currently therapies primarily treat symptoms. Also, although various novel drugs (e.g., proteins, peptides, siRNAs, synthetic chemicals, etc.) have been identified, however, most of these may not succeed due to the unsatisfied drug pharmacokinetics, and unspecific targeting and potentially increase side effects. The challenges come from biological barriers, especially the blood-brain barrier (BBB). BBB is the well-organized interface between the CNS and the peripheral circulation, which impedes influx of most compounds from blood to brain [4]. Composed by endothelial cells, astrocyte end-feet and pericytes, BBB strictly controls the transfer of molecules, ions and cells between the blood and the CNS. There are five main routes for any chemicals to transport across the BBB: the diffusive route by transcellular-lipoid bilayer membrane; transport carriers; specific receptor-mediated endocytosis and transcytosis; adsorptive transcytosis; paracellular-tight junctions. These pathways allow BBB protects CNS from toxins, pathogens, inflammation and maintains CNS homeostasis [5]. However, the restrictive nature of BBB also set a challenging obstacle for drug delivery to the CNS. It is also worth noticing that BBB dysfunction has been observed in most CNS diseases, including $\mathrm{AD}, \mathrm{PD}$ and stroke. Although it is uncertain whether $\mathrm{BBB}$ dysfunction is causal of diseases onset, changes of the transport system and enzymes is a vital contributor and exacerbator to the pathologies [5]. BBB compromise in CNS diseases also has significant implications for disease treatment. It is interesting to assume the intact BBB in CNS diseases will benefit drug delivery efficiency. However, this will be a controversial strategy as BBB dysfunction is an essential contributor to development of the disease.

However, nanotechnology has developed rapidly over recent decades and may have considerable potential advantages for CNS diseases diagnosis and treatment. Nanotechnology refers to the control or manipulation of engineered materials or devices organized at the nanometer scale (one billionth of a meter) to achieve unique functional proper- 
ties [6]. Indeed, the properties of nanomaterials are significantly different to those at their corresponding macroscale due to differences in arrangement and spacing of surface atoms and molecules [7].

Therefore, nanomaterials hold great potential for biomarker development, theranostics and therapeutics. First, modified nanomaterials can be used to target damaged cells and tissues via molecular-scale interactions. Nanoengineered materials can also simultaneously sustain drug release, enhance bioavailability, deliver multiple agents and protect compounds from degradation when surface modified with distinct molecules. Nanomaterials are also an excellent candidate to develop BBB bypass strategies, including carrying a surface functionalization to target and penetrate the BBB and increase half-life in blood. These nanomaterial properties place them at the forefront of future diagnostic and therapeutic opportunities for CNS diseases.

In this review, we provide an overview of recent studies applying nanotechnology to CNS diseases, in particular, neurodegenerative diseases (NDs) and stroke. Although extensive reviews on the application of nanotechnology against CNS diseases have emerged in recent years, most of these summarized the progresses with an emphasize on the chemical and structure aspects of nanomaterials. In this regard, balanced discussions are made to describe the disease pathogenesis and the mechanisms that make nanomaterials ideal candidates for early diagnosis and therapy. We also discuss the application of nanotechnology to the stimulation of adult neurogenesis, which would benefit most patients with CNS diseases.

\section{Nanotechnology in AD}

$\mathrm{AD}$ is characterized by progressive memory loss, emotional disturbances and impaired cognitive function associated with the degeneration and death of neurons in the limbic structures (hippocampus, amygdala and their associated cortices). There are two key neuropathological hallmarks of AD: intracellular neurofibrillary tangles formed from filaments of hyperphosphorylated Tau protein, and extracellular senile plaques formed by amyloid- $\beta$ (A $\beta$ ) peptide aggregation [8]. A multitude of genetic, pathological and biochemical studies suggest that $A \beta$ accumulation caused by imbalanced $A \beta$ production and clearance plays a central role in $A D$ pathogenesis [9]. As such, the ' $A \beta$ cascade hypothesis' has become widely accepted to explain $\mathrm{AD}$ pathogenesis [10]. According to this hypothesis, $\mathrm{A} \beta$ peptide accumulation triggers $\mathrm{AD}$ pathogenesis and leads to synaptic damage, neuronal death and cognitive deficits. Thus, $\mathrm{A} \beta$ has been targeted for $\mathrm{AD}$ diagnosis and therapy. In recent decades, nanotechnology-based therapeutic strategies such as modulating $A \beta$ production, inhibiting $A \beta$ aggregation and enhancing $A \beta$ clearance have been widely explored and amazing progress has been made (Figure 1 \& Table 1 ).

\section{Modulation of $A \beta$ production}

Modulation of $A \beta$ production is one of many effective approaches to reduce cerebral $A \beta$ levels. $A \beta$ is generated from the transmembrane amyloid precursor protein (APP) by proteolysis. During proteolysis, APP is first cleaved by secretase family proteases $-\alpha$-, $\beta$ - or $\gamma$-secretase - and, consequently, follows one of two different and exclusive pathways: amyloidogenic and nonamyloidogenic. In the amyloidogenic pathway, APP is cleaved by $\beta$-secretase ( $\beta$-site APP-cleaving enzyme-1 [BACE1]) at the N-terminus of the A $\beta$ domain, from which the APPs- $\beta$ fragment is generated and an APP C-terminal fragment ( $\beta$ CTF or C99) remains. The residual $\beta$-CTF is further cleaved by $\gamma$-secretase to release $A \beta$ and the APP intracellular domain. As $\gamma$-secretase has a number of cleavage sites, it generates variable length of $A \beta$ fragments (37-43 amino acids), with $A \beta_{42}$ being the most toxic. In the nonamyloidogenic pathway, APP is sequentially cleaved by $\alpha$-secretase and $\gamma$-secretase to release a soluble amino terminal fragment (APPs- $\alpha$ ) and a C-terminal fragment ( $\alpha$-CTF or C83). Unlike in the amyloidogenic pathway, $\alpha$-secretase cleaves APP in the middle of the $A \beta$ region, so no A $\beta$ is generated [11]. Nanoparticles (NPs) can be engineered to deliver siRNAs or other agents into neuronal cells to regulate secretase activity. In this way, nanotechnology-based strategies that decrease $A \beta$ production by modulating secretase expression may fundamentally alleviate $A \beta$-induced toxicity and have potential clinical utility.

As APP cleavage by BACE1 is the rate-limiting step in $\mathrm{A} \beta$ production, using BACE1 siRNA to suppress $\mathrm{BACE} 1$ is a logical approach to prevent $\mathrm{A} \beta$ production [11]. However, neuronal cell membranes and the $\mathrm{BBB}$ limit $B A C E 1$ siRNA entry into nerves. A recent study used fluorescent quantum dots (QDs) to deliver BACE1 siRNAs into SK-N-SH human neuroblastoma cells. Although immunogenicity and nonspecific delivery restricted the application of BACE1 siRNA, in this study, negatively charged siRNAs were electrostatically adsorbed to the surface of QDs to form QD-PEG/siRNA nanocomplexes, which freely crossed cell membranes and the BBB. The QD-PEG/siRNA nanocomplexes significantly inhibited AD-associated BACE1 gene expression by $51 \%$ in SK-N-SH cells [12]. Usefully, these QDs also provided a platform to monitor and track siRNA delivery due to 


\begin{tabular}{|c|c|c|c|c|c|}
\hline Nanomaterials & $\begin{array}{l}\text { Therapeutic } \\
\text { agent }\end{array}$ & Target ligand & Model & Outcome & Ref. \\
\hline $\begin{array}{l}\text { Fluorescent } \\
\text { quantum dots }\end{array}$ & BACE1 SIRNA & PEG & SK-N-SH cells & - Achieved gene silencing efficiency of almost $51 \%$ & [12] \\
\hline \multirow[t]{2}{*}{ Exosomes } & \multirow[t]{2}{*}{ BACE1 SiRNA } & \multirow[t]{2}{*}{ RVG and Lamp2b } & \multirow[t]{2}{*}{ C57BL/6 mice } & - Significantly decreased the total $A \beta_{1-42}$ levels & \multirow[t]{2}{*}{ [13] } \\
\hline & & & & - Significantly decreased BACE1 mRNA levels & \\
\hline $\begin{array}{l}\text { Nanolipidic } \\
\text { particles }\end{array}$ & EGCG & - & APPswe N2a cells & $\begin{array}{l}\text { - Improved the neuronal } \alpha \text {-secretase enhancing ability in } \\
\text { vitro up to } 91 \%\end{array}$ & [15] \\
\hline $\begin{array}{l}\text { Polystyrene } \\
\text { nanoparticles }\end{array}$ & - & $\begin{array}{l}\text { N2PY (the iron } \\
\text { chelator) }\end{array}$ & $\begin{array}{l}\text { Human cortical neuronal } \\
\text { cells }\end{array}$ & $\begin{array}{l}\text { - Significantly protected cells from } A \beta \text {-associated } \\
\text { cytotoxicity }\end{array}$ & [21] \\
\hline $\begin{array}{l}\text { POM@P } \\
\text { nanoparticles }\end{array}$ & - & $\begin{array}{l}\mathrm{A} \beta_{15-20} \text { and Congo } \\
\text { red }\end{array}$ & PC12 cells & - POM@P nanoparticles rescued $A \beta$-induced cytotoxicity & [23] \\
\hline Au nanorods & - & $P O M @ P$ and $A \beta_{15-20}$ & Mice cerebrospinal fluid & - Inhibited $A \beta$ aggregation under NIR irradiation & [24] \\
\hline Liposomes & - & $\begin{array}{l}\text { Cis-glycofused } \\
\text { benzopyran } \\
\text { compound }\end{array}$ & In solution & - Significantly inhibited $A \beta_{1-42}$ aggregation & [25] \\
\hline \multirow[t]{3}{*}{ PLA nanoparticles } & \multirow[t]{2}{*}{ Curcumin } & \multirow[t]{3}{*}{ PEG } & \multirow[t]{2}{*}{$\operatorname{Tg} 2576$ Mice } & $\begin{array}{l}\text { - Produced a tendency toward better working memory in } \\
\text { the radial arm maze test }\end{array}$ & \multirow[t]{2}{*}{ [27] } \\
\hline & & & & - Produced better cue memory in the fear condition test & \\
\hline & Selegiline & & In solution & $\begin{array}{l}\text { - The destabilizing effects of two types fibril }\left(f A \beta_{(1-40)} \text { and }\right. \\
\left.f A \beta_{(1-42)}\right) \text { were increased }\end{array}$ & [30] \\
\hline \multirow[t]{2}{*}{$W_{2}$ nanosheets } & \multirow[t]{2}{*}{ - } & \multirow[t]{2}{*}{-} & In solution & $\begin{array}{l}\text { - Inhibited } A \beta \text { aggregation and dissociated preformed } A \beta \\
\text { aggregates }\end{array}$ & \multirow[t]{2}{*}{ [31] } \\
\hline & & & PC12 cells & - Rescued $A \beta_{40}$-induced cytotoxicity & \\
\hline \multirow[t]{6}{*}{ Liposomes } & \multirow[t]{2}{*}{-} & \multirow{6}{*}{$\begin{array}{l}\text { Phosphatidic acid } \\
\text { and ApoE-derived } \\
\text { peptide }\end{array}$} & \multirow[t]{2}{*}{$A \beta$ solutions } & - Significantly inhibited $A \beta_{42}$ aggregation in solution & \multirow[t]{2}{*}{ [32] } \\
\hline & & & & $\begin{array}{l}\text { - Significant destabilization of } A \beta_{42} \text { aggregates was } \\
\text { observed in solution }\end{array}$ & \\
\hline & \multirow[t]{4}{*}{-} & & \multirow[t]{4}{*}{$A P P / P S 1 \mathrm{Tg}$ mice } & $\begin{array}{l}\text { - Insoluble and soluble } A \beta_{1-40} \text { was decreased by } 33 \text { and } \\
32 \% \text {, respectively; Insoluble and soluble } A \beta_{1-42} \text { was } \\
\text { decreased by } 26 \text { and } 11 \% \text {, respectively }\end{array}$ & \multirow[t]{4}{*}{ [33] } \\
\hline & & & & $\begin{array}{l}\text { - Strongly reduced the levels of soluble } A \beta \text { species with } \mathrm{MW} \\
\text { up to } 90 \mathrm{kDa}, 70.5 \%\end{array}$ & \\
\hline & & & & $\begin{array}{l}\text { - Reduced the number and total area of brain } A \beta \text { plaques } \\
\text { by } 34 \%\end{array}$ & \\
\hline & & & & $\begin{array}{l}\text { - Significantly recovered their long-term recognition } \\
\text { memory in Novel-object recognition test }\end{array}$ & \\
\hline \multirow[t]{5}{*}{$\begin{array}{l}\text { Lipoprotein-based } \\
\text { nanoparticles }\end{array}$} & \multirow[t]{5}{*}{-} & \multirow[t]{5}{*}{ ApoE3 } & $\begin{array}{l}\text { Primary microglia and } \\
\text { astrocytes culture }\end{array}$ & - Accelerated microglial and astroglial degeneration of $A \beta$ & \multirow[t]{5}{*}{ [43] } \\
\hline & & & \multirow[t]{4}{*}{ SAMP8 mice } & - Attenuated microgliosis & \\
\hline & & & & $\begin{array}{l}\text { - Amyloid plaques were markedly decreased in both the } \\
\text { cortices and hippocampi }\end{array}$ & \\
\hline & & & & $\begin{array}{l}\text { - Significantly attenuated impairment of neuronal integrity } \\
\text { and neuron loss }\end{array}$ & \\
\hline & & & & $\begin{array}{l}\text { - Significantly improved spatial learning and memory on the } \\
\text { measures of Morris water maze performance }\end{array}$ & \\
\hline Liposomes & - & $\begin{array}{l}\text { Phosphatidic acid } \\
\text { and ApoE-derived } \\
\text { peptide }\end{array}$ & $A P P / P S 1 \mathrm{Tg}$ mice & $\begin{array}{l}\text { - Significantly withdrawn } A \beta \text { peptides and increased plasma } \\
\text { A } \beta \text { levels }\end{array}$ & [45] \\
\hline $\begin{array}{l}\text { Chitosan } \\
\text { nanoparticles }\end{array}$ & - & $\begin{array}{l}\text { Intramembranous } \\
\text { fragment of } A \beta\end{array}$ & Kunming male mice & $\begin{array}{l}\text { - Had significantly more } \lg G \text { against } A \beta_{42} \text { in serum and a } \\
\text { lower titer of IgG against } A \beta_{42} \text { in the brain after the last } \\
\text { immunization }\end{array}$ & [47] \\
\hline PLGA nanoparticles & - & $A \beta_{1-15}$ peptide & Balb/c mice & - Enhanced immune responses and serum IgG levels & [48] \\
\hline \multirow[t]{2}{*}{$\begin{array}{l}\mathrm{CeO}_{2} \text { or ceria } \\
\text { nanoparticles or } \\
\text { nanoceria }\end{array}$} & \multirow[t]{2}{*}{-} & - & Primary cortical neurons & $\begin{array}{l}\text { - Reduced endogenous peroxynitrite and protected against } \\
\text { A } \beta \text {-induced mitochondrial fragmentation and neuronal cell } \\
\text { death }\end{array}$ & [54] \\
\hline & & PEG and $A \beta-M a b$ & $\begin{array}{l}A \beta_{1-42} \text {-induced } A D \\
\text { model cells }(\mathrm{SH}-\mathrm{SY} 5 \mathrm{Y} \\
\text { cells) }\end{array}$ & - Protected neurons against $A \beta$-mediated cytotoxicity & [56] \\
\hline
\end{tabular}

A $\beta$ : Amyloid- $\beta$; A $\beta-M a b: A \beta$ monoclonal antibody; ApoE: Apolipoprotein E; APP: Amyloid precursor protein; Au: Gold; BACE1: $\beta$-site APP-cleaving enzyme 1; EGCG: Epigallocatechin-3-gallate; LTP: Long-term potentiation; MW: Molecular weight; NIR: Near infrared; PEG: Poly(ethylene glycol); PLA: Polylactic acid; PLGA: Poly(lactic-co-glycolic acid); POM@P: Polyoxometalate; RAGE: Receptor for advanced glycation end products; RVG: Rabies viral glycoprotein; VP025: Phosphatidylglycerol-based phospholipid nanoparticles. 


\begin{tabular}{|c|c|c|c|c|c|}
\hline Nanomaterials & $\begin{array}{l}\text { Therapeutic } \\
\text { agent }\end{array}$ & Target ligand & Model & Outcome & Ref. \\
\hline \multirow[t]{2}{*}{ VP025 } & \multirow[t]{2}{*}{-} & \multirow[t]{2}{*}{-} & \multirow[t]{2}{*}{ Wister rats } & $\begin{array}{l}\text { - Significantly inhibited caspase-3 activation in hippocampal } \\
\text { tissues }\end{array}$ & \multirow[t]{2}{*}{ [57] } \\
\hline & & & & - Significantly attenuated the $A \beta$-induced depression in LTP & \\
\hline \multirow[t]{2}{*}{ Au nanoparticles } & \multirow[t]{2}{*}{ Anthocyanins } & \multirow[t]{2}{*}{-} & \multirow[t]{2}{*}{$\mathrm{A} \beta$-treated mice } & $\begin{array}{l}\text { - Attenuated } A \beta \text {-induced neuroinflammation and } \\
\text { neuroapoptosis }\end{array}$ & \multirow[t]{2}{*}{ [58] } \\
\hline & & & & $\begin{array}{l}\text { - Reduced the levels of A } \beta, B A C E-1 \text {, the microgliosis, } \\
\text { astrocytosis, and RAGE expression }\end{array}$ & \\
\hline PLGA nanoparticles & Dexibuprofen & PEG & APPswe/PS1dE9 mice & $\begin{array}{l}\text { - Reduced memory impairment more effectively and } \\
\text { decreased brain inflammation }\end{array}$ & [59] \\
\hline
\end{tabular}

A $\beta$ : Amyloid- $\beta$; A $\beta-M a b: A \beta$ monoclonal antibody; ApoE: Apolipoprotein E; APP: Amyloid precursor protein; Au: Gold; BACE1: $\beta$-site APP-cleaving enzyme 1; EGCG: Epigallocatechin-3-gallate; LTP: Long-term potentiation; MW: Molecular weight; NIR: Near infrared; PEG: Poly(ethylene glycol); PLA: Polylactic acid; PLGA: Poly(lactic-co-glycolic acid); POM@P: Polyoxometalate; RAGE: Receptor for advanced glycation end products; RVG: Rabies viral glycoprotein; VP025: Phosphatidylglycerol-based phospholipid nanoparticles.

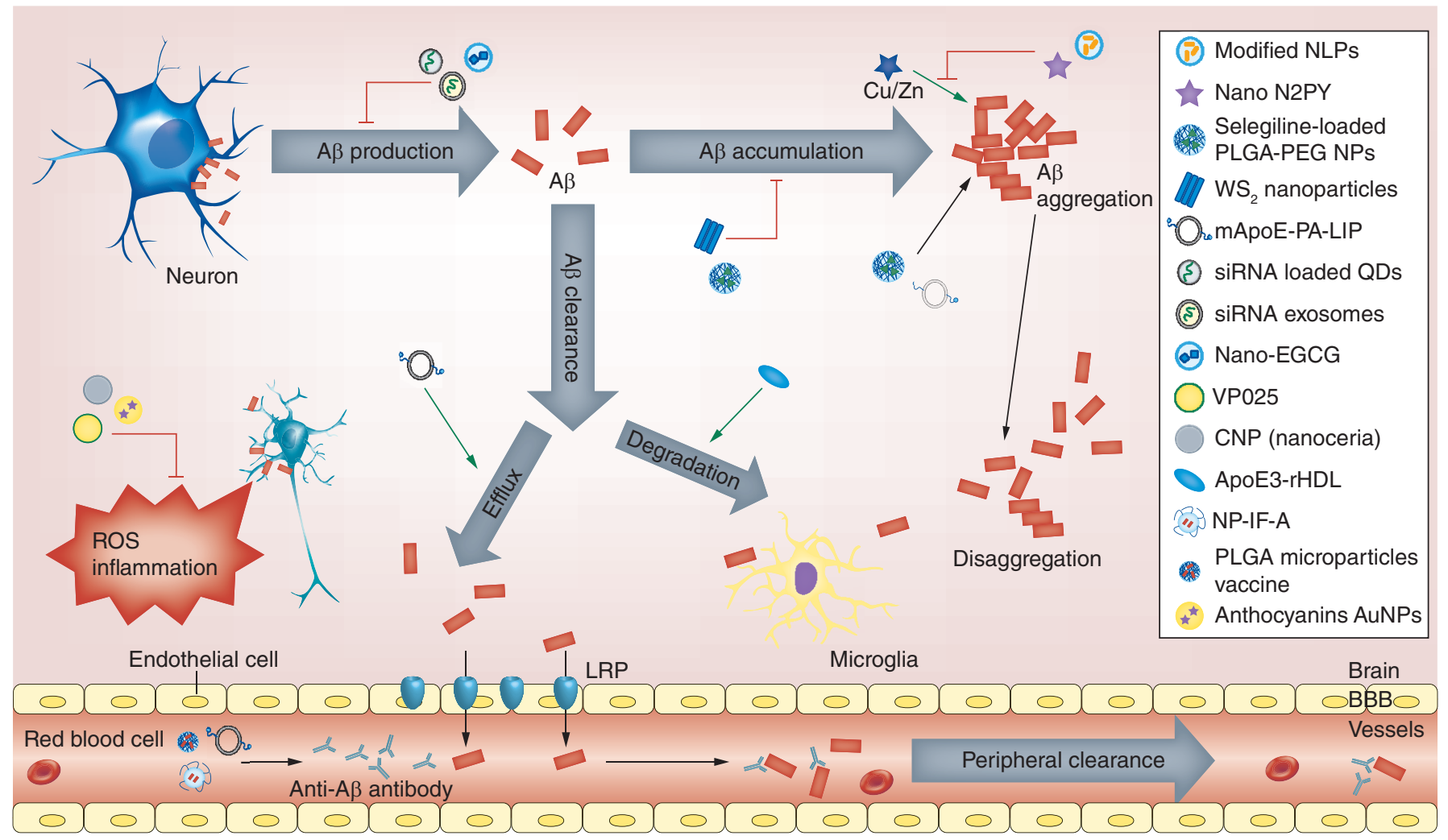

Figure 1. Schematic diagram of the nano-therapy strategies in Alzheimer's disease.

BBB: Blood-brain barrier; LRP: Lipoprotein receptor-related protein; PLGA: Poly(lactic-co-glycolic acid); QD: Quantum dot; ROS: Reactive oxygen species.

their unique spectroscopic properties [12]. Alvarez-Erviti et al. [13] also successfully delivered BACE1 siRNA into mouse brains using modified exosomes, which are endogenous transporting nanovesicles measuring 40-100 nm in diameter. To reduce immunogenicity, exosomes were prepared from self-derived immature murine dendritic cells and were further modified with the neuron-specific rabies viral glycoprotein (RVG) peptide fused to Lamp2b (an exosomal membrane protein) to promote specific targeting. These modified exosomes were then loaded with $B A C E 1$ siRNA by electroporation, and they specifically delivered siRNA to central neurons in normal C57BL/6 mice. The therapeutic potential of exosome-mediated siRNA delivery using this method was demonstrated by successful mRNA (60\%) and protein (62\%) knockdown of $B A C E 1$ together with a $55 \%$ reduction in total $A \beta_{1-42}$ levels [13]. 
The nonamyloidogenic pathway has also been proposed as an alternative target to reduce $\mathrm{A} \beta$ production. Epigallocatechin-3-gallate (EGCG) was shown to enhance the nonamyloidogenic pathway via the PI3K/Akt pathway; however, in practice, poor bioavailability limited its use [14]. Smith $e$ t al. [15] recently applied lipid-based NPs functionalized with EGCG (EGCG NPs) to increase $\alpha$-secretase activity and EGCG bioavailability and found that EGCG NPs doubled the oral bioavailability of EGCG in rats and improved $\alpha$-secretase activity by up to $91 \%$ in APPswe N2a-mutant APP neuroblastoma cells [15].

Theoretically, NPs can be used to modulate $A \beta$ production via three pathways that control secretase activity: inhibition of $\beta$-secretase, inhibition of $\gamma$-secretase, or activation of $\alpha$-secretase. However, inhibition of $\gamma$-secretase has been reported to interfere with numerous physiological processes, leading to serious side effects [16]. In contrast, there has been great progress in targeting $\alpha$ - and $\beta$-secretase using NPs [17], although long-term safety is still unknown with further studies required.

\section{Inhibition of $A \beta$ aggregation}

$A \beta$ monomers can spontaneously aggregate to form oligomers and fibrils. Unlike $A \beta$ monomers, $A \beta$ oligomers are toxic in $\mathrm{AD}$ [18]. Thus, inhibiting $\mathrm{A} \beta$ aggregation or dissolving $\mathrm{A} \beta$ aggregates may slow or even stop $\mathrm{AD}$ progression. Nanotechnology-based strategies are attractive and promising for this purpose due to the potential to engineer and conjugate metal chelators, $A \beta$-binding peptides, $A \beta$ peptide ligands and other small molecules.

Numerous studies have shown that zinc, copper and iron are markedly enriched in $A \beta$ deposits. Furthermore, the interaction between specific metals (particularly iron and copper) and $A \beta$ can promote $A \beta$ peptides to form dityrosine cross-linked oligomers $[19,20]$, thereby accelerating $A \beta$ deposition. As such, metal chelators act as potent inhibitors of $A \beta$ aggregation through disruption of $A \beta$ oligomer formation. Unfortunately, the $B B B$ and metal chelator neurotoxicity limit their utility. However, NPs might overcome these limitations to inhibit A $\beta$ aggregation. Recently, nanoparticle-chelator conjugates (nano-N2PY) have been reported to protect human cortical neurons from $\mathrm{A} \beta$ induced toxicity by inhibiting $A \beta$ aggregation [21]. Another interesting study reported that nanoliposomes modified with different chelating ligands such as copper acetate, histidine, zinc acetate and ethylenediaminetetraacetic acid disaggregated and resolubilized $\mathrm{Cu}-\mathrm{A} \beta_{1-42}$ and $\mathrm{Zn}-\mathrm{A} \beta_{1-42}$ aggregates in PC12 neuronal cells. This finding suggests that chelating ligand-bound NPs can protect neuronal cells from $\mathrm{A} \beta$ aggregation-induced toxicity [22].

Besides metal chelators, polyoxometalates (POMs) form a class of early transition metal oxygen anion NPs engineered to hybridize with $\mathrm{A} \beta_{15-20}$ peptide (POM@P nanospheres) and prevent $\mathrm{A} \beta$ aggregation. These bifunctional POM@P nanospheres acted as nanoclusters to inhibit $A \beta$ aggregation in mouse cerebrospinal fluid (CSF) and rescued A $\beta$-induced cytotoxicity in PC12 neuronal cells. POM@P nanospheres also acted as effective fluorescent probes to monitor their inhibitory effects by Congo red (an A $\beta$ fibril stain) fluorescence changes [23]. More recently, POMs were loaded with another $A \beta$ inhibitor, $A \beta_{15-20}$, to form self-assembling peptide-conjugated gold (Au) nanorods, which acted as effective diagnostic probes to detect $A \beta$ aggregation. These integrated, three-segment NPs (an $A \beta$-targeting element, a reporter and inhibitor) effectively inhibited $A \beta$ aggregation, dissociated amyloid deposits with near-infrared irradiation and were effective and highly sensitive diagnostic probes to detect $A \beta$ aggregates in mouse CSF [24]. Hence, these NPs might have potential as future theranostic tools for the treatment and monitoring of $\mathrm{AD}$, although further in vivo studies are required.

Another good example of a nano-based agent for halting $A \beta$ aggregation are cis-glycofused benzopyran-decorated nanoliposomes. The cis-glycofused benzopyran was applied as an $A \beta$ ligand and linked to nanoliposomes, resulting in improved stability and binding affinity. As expected, the decorated nanoliposomes significantly inhibited and delayed $\mathrm{A} \beta_{1-42}$ aggregation in vitro [25].

Apart from $A \beta$ peptide ligands, other small molecules have been bound to NPs to prevent A $\beta$ aggregation. For example, curcumin, a potent anti-inflammatory and antioxidant compound, can modulate multiple targets implicated in the pathogenesis of NDs and stroke [26]. However, its poor bioavailability and stability have limited its application in preventing $A \beta$ aggregation. Cheng et al. [27] developed curcumin-decorated polyethylene glycolpolylactic acid (PEG-PLA) NPs to overcome these disadvantages. Encouragingly, after administering these NPs to Tg2576 AD mice, memory impairments were greatly improved as reflected by radial arm maze and contextual fearconditioning testing, although plaque densities were not obviously altered [27]. In addition, curcumin inhibited the formation of fibrillar and oligomeric $\mathrm{A} \beta$ in vitro by attaching to the nanoliposome surface [28]. Natural compounds loaded to NPs have a great potential to inhibit $A \beta$ aggregation. Indeed, there is one excellent review that summarized the application of nanocarriers to load various natural compounds in treating various NDs [29]. In this review, we only selected some iconic examples focusing on the neurobiology mechanism behind the function. 
Dissolving $A \beta$ aggregates represents another approach for reversing $A \beta$ aggregate-induced toxicity. NPs decorated with the small-molecule selegiline, a selective monoamine oxidase-B inhibitor, were reported to dissolve $A \beta$ aggregates. In an encouraging study, selegiline was loaded on polylactic-co-glycolic acid-PEG (PLGA- $b$-PEG) NPs (selegiline-loaded PLGA- $b$-PEG NPs) to dissolve existing A $\beta$ aggregates. The destabilizing effect of selegiline-loaded PLGA- $b$-PEG NPs on $A \beta$ fibril $\left(A \beta_{1-40}\right.$ and $\left.A \beta_{1-42}\right)$ formation was observed in vitro [30]. Another study applied $\mathrm{WS}_{2}$ nanosheets, a transition metal dichalcogenide nanomaterial, to inhibit $A \beta$ aggregation. $\mathrm{WS}_{2}$ nanosheets crossed the $\mathrm{BBB}$ to selectively absorb $\mathrm{A} \beta_{40}$ monomers through van der Waals and electrostatic interactions, thereby inhibiting $A \beta$ aggregation and dissolving $A \beta_{40}$ fibrils through their uniquely high near-infrared absorption [31].

Bifunctionalized liposomes have also been used to dissolve $A \beta$ aggregates. These bifunctionalized liposomes were decorated with a modified peptide derived from the receptor-binding domain of human apolipoprotein $\mathrm{E}(\mathrm{mApoE})$ to bind the $\mathrm{BBB}$, and phosphatidic acid (PA) to bind $\mathrm{A} \beta$ (mApoE-PA-LIP). mApoE-PA-LIP crossed the BBB, inhibited $A \beta$ aggregation and triggered disaggregation of $A \beta$ aggregates in vitro, implying that $m A$ poE-PA-LIP is a robust inhibitor of $A \beta$ deposition [32]. Further studies of mApoE-PA-LIP focused on reducing $A \beta$ burden and ameliorating memory impairment in AD model mice. Amazingly, administration of mApoE-PA-LIP for 3 weeks (three injections per week) displayed the unique capacity to decrease total $A \beta_{1-42}$, especially its oligomeric forms $(-70.5 \%)$, in $A P P / P S 1 \mathrm{AD}$ model mice. As a result, impaired memory was improved when tested by the novel object recognition test [33].

Of the NPs that inhibit $A \beta$ aggregation, AuNPs deserve special mention due to their unique physicochemical properties suitable for medical applications [34]. AuNPs hinder A $\beta$ aggregation when conjugated with the A $\beta$-binding peptide. Kogan et al. [35] conjugated AuNPs with H-Cys-Leu-Pro-Phe-Phe-Asp- $\mathrm{NH}_{2}$ (Cys-PEP, an A $\beta$-binding peptide). The AuNP complexes dissolved $A \beta$ deposits in solution when heated locally or remotely [35]. Furthermore, AuNPs conjugated with the $A \beta$-binding petite CLPFFD irreversibly inhibited amyloidogenesis by $A \beta$ in solution under microwave irradiation [36]. The Kogan group conjugated both CLPFFD and THRPPMWSPVWP (THR, a peptide targeting the $\mathrm{BBB}$ ) to the surface of AuNPs to target BBB receptors (AuNPs-THR-CLPFFD). These modified AuNPs possessed improved BBB permeability, providing hope for further therapeutic application [37]. More recently, Au nanorods modified with D1 peptide (to bind A $\beta$ ) and Angiopep-2 (to penetrate the BBB) have been reported to decrease $\mathrm{A} \beta$ toxicity in a Caenorhabditis elegans $\mathrm{AD}$ model [38]. Although exactly how these Au nanorods modulate $A \beta$ aggregation remains unclear, they offer promising new alternatives for the treatment of $A D$ and other amyloidogenic diseases.

Due to their great biocompatibility and easy conjugation with other chemical entities, AuNPs have huge potential in diagnostics and therapeutics. Note, however, that considerable further clinical development is still required to translate AuNPs for clinical benefit.

Improvement of $A \beta$ clearance

Typically, $A \beta$ clearance is achieved via two major pathways: enzymatic degradation and receptor-mediated clearance. In the enzymatic degradation pathway, microglia and astrocytes internalize and degrade cerebral A $\beta$. In the receptormediated clearance pathway, $\mathrm{A} \beta$ either directly binds to low-density lipoprotein receptor-related protein (LRP) or indirectly binds to LRP by attaching LRP ligands such as ApoE to transport A $\beta$ across the BBB and out of the brain [39]. In $A D$ patients, especially late-onset $A D$ patients, $A \beta$ clearance is impaired overall [40]. Thus, promoting $A \beta$ clearance is a prospective approach to reduce $A \beta$ toxicity. Currently, removing $A \beta$ with $A \beta$-specific antibodies (Abs) is relatively efficient but is known to cause autoimmune-related adverse effects [41]. Nanotechnology-based strategies are highly efficient as they promote both clearance pathways. In the enzymatic degradation pathway, the remolded NPs accelerate glia-mediated $A \beta$ degradation. In the receptor-mediated pathway, NPs facilitate receptor-mediated $\mathrm{A} \beta$ efflux due to their high binding affinity to $\mathrm{A} \beta$ peptides and improved and simultaneous targeting of LRP or LRP ligands. Improving the peripheral clearance of $A \beta$ directly or indirectly also contributes to receptor-mediated $\mathrm{A} \beta$ efflux. As such, this nanotechnology approach has been explored extensively for AD treatment.

High-density lipoproteins (HDLs) have also been widely investigated for accelerating A $\beta$ degradation. HDLs have many advantages, including their ultrasmall size (8-12 nm diameter), long half-life and specific targeted delivery [42]. Song et al. recently reported that ApoE3-reconstituted HDL (ApoE3-rHDL) showed high affinity to both monomeric and oligomeric $A \beta$. This approach can be used to efficiently transport $A \beta$ to microglia and astroglia lysosomes, thereby accelerating $A \beta$ degradation. After intravenous injection into SAMP8 mice for 4 weeks, ApoE3-rHDL was found bound to circulating $A \beta$ and facilitated $A \beta$ degradation in liver cells. Amazingly, reduced $\mathrm{A} \beta$ deposits, ameliorated neurologic changes and attenuated microgliosis were also observed in SAMP8 mouse 
brains [43]. Encouragingly, Morris water maze results suggested that ApoE3-rHDL also rescued deficits in spatial learning and memory in ApoE3-rHDL-treated SAMP8 mice [43].

In the receptor-mediated efflux pathway, $A \beta$ not only enters the bloodstream by interacting with LRP but also re-enters the brain from the plasma through the receptor for advanced glycation end products, suggesting that $A \beta$ exists in equilibrium in the brain and the plasma [39]. This equilibrium may be interrupted by $A \beta$ sequestration in plasma to create a peripheral sink and increased efflux of soluble $A \beta$ from the brain [44]. Thereby, approaches that directly deliver $A \beta$ out of the brain or scavenge $A \beta$ from the bloodstream are effective at preventing $A \beta$ accumulation. mApoE-PA-LIP is capable of facilitating $A \beta$ efflux from brain to bloodstream and can accelerate peripheral $\mathrm{A} \beta$ clearance in $A P P / P S 1$ mice [33]. For insoluble $\mathrm{A} \beta$ aggregates (i.e., fibrils and plaques), $\mathrm{mApoE}-$ PA-LIP can destabilize them into soluble $A \beta$, allowing their transport from the brain into the circulation before peripheral clearance. A more recent study reported that mApoE-PA-LIP can delay AD symptom progression and prevent memory impairment in presymptomatic-stage AD mice [45]. More specifically, mApoE-PA-LIP promoted brain $A \beta$ clearance by the peripheral 'sink' effect, thereby improving $A \beta$ turnover in the brain and slowing down $A \beta$ accumulation. Furthermore, no toxicity was observed. These findings imply that mApoE-PA-LIP may represent a new, 'all-in-one' NP to combat $A \beta$ accumulation $[32,33,46]$.

Besides directly promoting peripheral A $\beta$ clearance by mApoE-PA-LIP [33], immunization is another proposed $A \beta$ clearance approach. Active (immunizing with $A \beta$ peptides) and passive (by administrating anti- $A \beta$ Abs) $A \beta$ immunizations are commonly used strategies to promote peripheral $A \beta$ clearance. The application of nanotechnology to immunization affords many advantages including controlled antigen release and stabilized vaccine antigens. Based on these benefits, Songjiang and Lixiang [47] exploited chitosan microsphere as an $A \beta$ nanocarrier, which was loaded with an $A \beta$ fragment (NP-IF-A) to function as a vaccine. As a result, NP-IF-A successfully activated an immunization response in mice [47]. Similarly, $A \beta_{1-15}$ peptides encapsulated in PLGA NPs enhanced serum Abs responses; Balb/c mice immunized with $\mathrm{A} \beta_{1-15}$-loaded PLGA NPs had high circulating anti-A $\beta$ Abs comparable to the response induced by the potent Freund's adjuvant [48]. Compared with active immunotherapy, anti-A $\beta$ monoclonal $A b(A \beta-m A b)$-decorated liposomes had higher affinities for $A \beta$ monomers and fibrils [49], and $A \beta-m A b$ nanoliposomes dramatically reduced circulating and brain levels of $A \beta_{1-40}$ and $A \beta_{1-42}$ in $A P P / P S 1$ mice. In addition, the ratio of phosphorylated to total Tau and the levels of glial fibrillary acidic protein and reactive glia decreased after $\mathrm{A} \beta-\mathrm{mAb}$ nanoliposome treatment [50]. In order to functionalize and personalize $\mathrm{AD}$-specific nanomedicines, further studies could focus on how to combine $A \beta-m A b$ nanoliposomes with brain-targeting ligands to directly target $\mathrm{A} \beta$ deposits in the brain.

\section{Targeting other AD pathogenesis}

Ongoing efforts to understand $\mathrm{AD}$ pathogenesis revealed several other hypotheses, including synaptic alterations, microglia and astrocyte activation, impairment of iron homeostasis and oxidative injury. The final common pathway is neuronal death and dementia associated with clinical symptoms [51,52]. Therefore, methods targeting those pathogenesis would be expected to protect against $\mathrm{AD}$ pathogenesis.

Cerium oxide NPs (CNPs, also called nanoceria or $\mathrm{CeO}_{2}-\mathrm{xNPs}$ ) are a widely recognized antioxidant in chronic inflammation and degenerative diseases [53] that have been reported to resist mitochondrial fragmentation and neuronal cell death. Nanoceria can switch between their $3^{+}$and $4^{+}$states to scavenge superoxide anions, hydrogen peroxide and peroxynitrite, which contribute to oxidative stress [54]. Therefore, nanoceria has emerged as a promising therapeutic for various NDs [55]. A recent study reported that nanoceria showed excellent capacity for scavenging reactive nitrogen species, especially tyrosine-nitrated protein (a biomarker of nitric oxide-dependent oxidative stress), and rescued cortical neurons from S-nitrosocysteine-induced death [54]. In another finding, PEG and anti$\mathrm{A} \beta$ Abs-coated CNPs (A $\beta$-CNPs-PEG) protected against oxidative stress/A $\beta$-mediated neurodegeneration through the brain-derived neurotrophic factor (BDNF) signaling pathway [56]. Another study found that anti-inflammatory phosphatidylglycerol-based phospholipid NPs (VP025) attenuated A $\beta$-induced long-term potentiation deficits by inhibiting caspase-3 activation [57]. Recent efforts have focused on exploiting NPs as drug carriers into the brain. For instance, anthocyanin-conjugated AuNPs have been shown to reduce $\mathrm{A} \beta$-induced neuroinflammation and apoptosis by inhibiting the $\mathrm{p}-\mathrm{JNK} / \mathrm{NF}-\mathrm{KB} / \mathrm{p}-\mathrm{GSK} 3 \beta$ pathway in both in vivo and in vitro $\mathrm{AD}$ models without significant neuronal cytotoxicity [58]. Another study used dexibuprofen-loaded nanospheres, which reduced memory impairment and decreased brain inflammation and $\mathrm{A} \beta$ plaque formation in APPswe/PS1dE9 mice [59].

In summary, each step of $A \beta$ production, aggregation and clearance can be a considered potential target to overcome amyloid formation-induced toxicity. As such, nanotechnology has been applied to target $A \beta$ and 
its aggregated forms. Exciting progress has been made in this area, with positive outcomes in modulating $A \beta$ production, inhibiting $A \beta$ aggregation, enhancing $A \beta$ clearance and even reversing $A \beta$-induced learning and memory deficits in AD model mice. Also, targeting other $\mathrm{AD}$ pathogenesis, such as inflammation and oxidative stress by nanotechnology is a promising approach to manage, delay and even treat AD.

\section{Detection of AD biomarkers}

The clinical diagnosis of $\mathrm{AD}$ is typically based on medical history, which includes cognitive function, neurological and general physical examination, and routine laboratory analyses [60]. However, before AD dementia presents and is diagnosed, $\mathrm{AD}$ pathophysiology may have been present for many years or even decades. Hence, $\mathrm{AD}$ progression can be regarded as having two key stages: preclinical and clinical. In the preclinical stage, AD biomarkers are present but insufficient to produce neuronal death and dementia symptoms [61], so treatment received at this stage would be optimal. AD biomarker detection is critical for the early diagnosis of $\mathrm{AD}$ and to develop efficient treatment strategies to slow or halt disease development, delay AD-associated dementia and to monitor treatment outcomes. Compared with conventional AD biomarkers, nanotechnology offers several advantages in this area.

\section{$A \beta$ detection}

As discussed above, $\mathrm{A} \beta$ peptide accumulation is regarded as a key contributor to early $\mathrm{AD}$ pathophysiology. The surface modification of NPs with various molecules such as A $\beta$-binding peptides and high-affinity compounds has great potential to boost diagnostic sensitivity and accuracy. The application of nanotechnology to $A \beta$ detection has focused on targeting $A \beta$ in the plasma and CSF and neuroimaging $A \beta$ deposition. Among various high-sensitivity technologies, an ultrasensitive assay established by the Georganopoulou's group was highly efficient. In this method, AuNPs were utilized for biobarcode assaying to determine the concentration of $A \beta$-derived diffusible ligands, a potential soluble pathogenic AD marker. The detection accuracy of his method was as high as $0.1 \mathrm{fM}$ [62]. Roney et al. [63] designed polymeric $n$-butyl-2-cyanoacrylate (PBCA) NPs to encapsulate the radiolabeled amyloid affinity drug ${ }^{125}$ I-clioquinol (CQ, 5-chloro-7-iodo-8-hydroxyquinoline). They showed that ${ }^{125}$ I -CQ-PBCA NPs crossed the $\mathrm{BBB}$ and exhibited significantly greater brain uptake and retention of the imaging agent in $\mathrm{AD}$ transgenic mice compared with wild-type controls [63]. Furthermore, ultrasmall superparamagnetic iron oxide NPs chemically coupled with $\mathrm{A} \beta$ detected amyloid deposition through magnetic resonance microimaging in $\mathrm{AD}$ transgenic mice, albeit with some safety concerns [64].

Agents with high affinity for $A \beta$ are crucial for the development of potential novel therapeutics and diagnostics. Numerous molecules have been studied for improving $A \beta$ affinity when decorating NPs, including PA or cardiolipin (22-60 nM) [65], curcumin (1-5 nM) [66], A $\beta$-mAb-decorated PACA NPs (700 pM for monomers and 300 pM for fibrils) [67] and $A \beta$-mAb-attached nanoliposomes (500 pM for fibrils) [49,68]. Additionally, Brambilla's group demonstrated that PEGylated NPs exhibited a high affinity for both soluble and serum A $\beta$ monomers and soluble oligomers and possessed a drastically increased blood half-life [68]. Although advances have been made in improving the affinity of agents for $\mathrm{A} \beta$, the $\mathrm{BBB}$ remains a major obstacle to their application in vivo. Therefore, bifunctionalized NPs that bind to $A \beta$ and penetrate the BBB hold great promise for therapeutic and diagnostic purposes. To this end, Salvati et al. [69] developed dual-functional nanoliposomes decorated with both PA (to bind A $\beta$ ) and the antitransferrin receptor $\mathrm{Ab}$ (RI7217), the latter chosen because transferrin receptors are expressed on the BBB and are typically considered a target for BBB transportation. These dual-function nanoliposomes showed enhanced $\mathrm{BBB}$ permeability in an in vitro $\mathrm{BBB}$ model and higher affinity for $\mathrm{A} \beta$ as evaluated by surface plasmon resonance [69]. Analogously, PEG-PLA NPs simultaneously decorated with A $\beta$-binding peptide (QSHYRHISPAQVC) and BBBtargeting ligand (TGNYKALHPHNGC) stained amyloid deposits in the sub-micromolar range in the brains of $\mathrm{AD}$ model mice and humans [70]. Moreover, nanoliposomes decorated with methoxy-XO4 (XO4), a highly specific $\mathrm{A} \beta$ plaque ligand, acted as a targeting moiety and fluorescent marker. After intravenous injection into APP/PS1 mice, XO4-decorated nanoliposomes crossed the $\mathrm{BBB}$ and bound to $\mathrm{A} \beta$ plaque deposits in both parenchymal and vascular areas [71].

Therefore, using NPs to target $A \beta$ has great potential to accelerate the development of AD treatment and diagnosis. Both therapeutic and diagnostic strategies urgently require novel technologies to specifically target $A \beta$. Nanotechnology represents a promising approach for $A \beta$ detection both in solution and in living animals. Future studies will no doubt continue to explore nanotechnology-based materials to accurately detect A $\beta$. 


\section{Tau detection}

According to the National Institute of Aging-Alzheimer's Association guidelines, evidence of amyloid positivity and presence of Tau or phospho-Tau in the CSF support the diagnosis of progression toward AD-related neuronal injury [72].

Early studies revealed that AuNPs are ultrasensitive and highly selective for detecting Tau protein $(<195 \mathrm{pg} / \mathrm{ml})$ in CSF when using its two-photon Rayleigh scattering properties. Furthermore, when AuNPs are coated with anti-Tau Abs, two-photon Rayleigh scattering intensity increases about 16-fold [73]. AuNP-based immuno-PCR (nano-iPCR) had superior sensitivity for the detection of Tau protein in human CSF samples [74]. Furthermore, polyclonal anti-Tau protein-immobilized AuNPs and monoclonal anti-Tau-functionalized hybrid magnetic NPs (MNPs) were combined in a sandwich assay for ultrasensitive and selective Tau detection. These two types of NP were regarded as the recognition and surface-enhanced Raman scattering components, respectively, and the detection limit for this sandwich assay was less than $25 \mathrm{fM}$ [75].

It is commonly accepted that $\mathrm{A} \beta$ and Tau are particularly relevant to early-stage $\mathrm{AD}$ pathophysiology. Although currently available methods such as neuroimaging, ELISA and PCR can detect pathological A $\beta$ and/or Tau protein, they have not yet extended to point-of-care use due to the need for high expertise, complicated operations and the challenge of low detection limits [76]. Hopefully, future research will focus on applying nanotechnology to detect these biomarkers in a molecular range, as this holds great promise for translation to clinical use and improving patient outcomes.

\section{Nanotechnology in PD}

$\mathrm{PD}$ is a common ND that presents with a constellation of symptoms including muscle rigidity, resting tremor, postural instability and slowing of physical movement (bradykinesia) [77]. Pathologically, PD is characterized by the progressive loss of dopaminergic neurons in the substantia nigra pars compacta (SNC) together with the existence of fibrillar $\alpha$-synuclein inclusions, known as Lewy bodies [78]. Loss of dopaminergic neurons in the SNC, which leads to dopamine (DA) depletion, is regarded as the underlying cause of degenerative motor symptoms in PD. Currently available treatments are based on DA replacement, particularly with L-3,4-dihydroxyphenylalanine (levodopa or $\mathrm{L}$-dopa, the precursor of DA) [79]. Although levodopa is an effective medicine for PD patients, especially during the early stages of the disease, long-term levodopa use may lead to motor complications such as dyskinesia and fluctuations in motor response [80]. Furthermore, although DA replacement relieves symptoms, it does not delay disease progression. These unsatisfying therapeutic results have led to numerous studies that aim to find efficient neuroprotective strategies that slow, stop or even reverse the progression of PD. Although the exact pathogenesis of $\mathrm{PD}$ is not clear, many studies suggest that misfolding protein aggregation, ubiquitin-proteasome system (UPS) impairment, mitochondrial dysfunction, oxidative stress and inflammation may all contribute to dopaminergic cell death in PD [81]. These molecular pathways are potential targets for neuroprotection. In this respect, nanotechnology could provide the convenience of drug delivery, controlled agent release, enhanced BBB permeability and specific cell targeting. Nanotechnology-based neuroprotection strategies including targeting $\alpha$-synuclein accumulation, oxidative stress, mitochondrial dysfunction, inflammation and growth factor supplementation hold great promise for PD treatment. Therefore, the application of nanotechnology in both DA replacement and neuroprotection presents a wide range of possibilities for PD (Figure $2 \&$ Table 2).

\section{DA replacement}

DA deficiency is the key neurochemical abnormality in early-stage PD. To date, the most effective approach for relieving disease symptoms is replenishment of depleted DA. Levodopa administration remains the standard clinical treatment for PD. However, levodopa has a relatively short half-life in plasma, resulting in the need for frequent levodopa administration over the long term to maintain its therapeutic effect, which can cause fluctuating plasma levodopa and striatal DA levels. Fluctuating levodopa plasma levels causes nonphysiological pulsatile stimulation of striatal DA receptors, consequently inducing response failures and motor complications such as dyskinesia [82,83]. NPs have been engineered to control levodopa release and have a longer half-life, thereby reducing drug dose and the risk of levodopa-induced dyskinesia.

$\mathrm{Zn} /$ Al-layered double hydroxides, a novel layered organic-inorganic nanocomposite material was synthesized to incorporate levodopa. This levodopa-incorporated nanocomposite showed excellent sustained release performance, indicating the potential to reduce the pulsatile stimulation of dopaminergic neurons [84]. Gambaryan et al. [85] applied PLGA NPs loaded with levodopa (nano-DOPA) to increase PD treatment efficiency. In the study, the 


\begin{tabular}{|c|c|c|c|c|c|}
\hline Nanomaterials & $\begin{array}{l}\text { Therapeutic } \\
\text { agent }\end{array}$ & Target ligand & Model & Outcome & Ref. \\
\hline \multirow[t]{4}{*}{ PLGA nanoparticles } & L-dopamine & - & \multirow{4}{*}{$\begin{array}{l}\text { 6-OHDA- } \\
\text { lesioned } \\
\text { rats }\end{array}$} & $\begin{array}{l}\text { - Significantly heightened placing task scores } \\
\text { - Restored the motor function in foot-fault asymmetry test }\end{array}$ & [85] \\
\hline & \multirow[t]{3}{*}{ Dopamine } & \multirow[t]{3}{*}{-} & & - Significantly decreased amphetamine-induced rotations & \multirow[t]{3}{*}{ [86] } \\
\hline & & & & - Restored the decrease of locomotor activity & \\
\hline & & & & - No additional mitochondrial damage or ultrastructural changes & \\
\hline \multirow[t]{3}{*}{$\mathrm{Fe}_{3} \mathrm{O}_{4}$ nanoparticles } & \multirow[t]{3}{*}{ NGF and shRNA } & \multirow{3}{*}{$\begin{array}{l}\mathrm{N}- \\
\text { isopropylacrylamide } \\
\text { derivative }\end{array}$} & \multirow{3}{*}{$\begin{array}{l}\mathrm{MPP}^{+} \text {-induced } \\
\mathrm{PD} \text { model mice }\end{array}$} & - Improved locomotor activity & \multirow[t]{3}{*}{ [92. } \\
\hline & & & & $\begin{array}{l}\text { - Remarkably decreased the mRNA levels of } \alpha \text {-synuclein and } \\
\text { enhanced TH mRNA levels }\end{array}$ & \\
\hline & & & & $\begin{array}{l}\text { - Upregulated TH expression and downregulated } \alpha \text {-synuclein } \\
\text { expression }\end{array}$ & \\
\hline \multirow[t]{8}{*}{ VP025 } & \multirow[t]{8}{*}{-} & \multirow[t]{8}{*}{-} & \multirow{3}{*}{$\begin{array}{l}\text { Proteasome } \\
\text { inhibitor treated } \\
\text { rats }\end{array}$} & $\begin{array}{l}\text { - Significantly decreased time spent in the amphetamine-induced } \\
\text { accelerating rotarod }\end{array}$ & \multirow[t]{3}{*}{ [94] } \\
\hline & & & & - Prevented the decrease in spontaneous locomotor activity & \\
\hline & & & & - Restored the dopamine for 6 weeks & \\
\hline & & & \multirow{5}{*}{$\begin{array}{l}\text { 6-OHDA- } \\
\text { lesioned } \\
\text { rats }\end{array}$} & $\begin{array}{l}\text { - Significantly induced the reduction of amphetamine-induced } \\
\text { rotation rates }\end{array}$ & \multirow[t]{5}{*}{ [95] } \\
\hline & & & & - Significantly spared striatal dopamine & \\
\hline & & & & - Rescued considerable ipsilateral nigral dopaminergic neurons & \\
\hline & & & & - Significantly reduced ipsilateral microglial activation & \\
\hline & & & & $\begin{array}{l}\text { - Significantly reduced p38 activation, which can mediate } \\
\text { apoptotic cell death }\end{array}$ & \\
\hline \multirow{4}{*}{$\begin{array}{l}\text { Dendrigraft } \\
\text { poly-L-lysines }\end{array}$} & \multirow{4}{*}{$\begin{array}{l}\text { Caspase-3 } \\
\text { shRNA }\end{array}$} & \multirow{4}{*}{$\begin{array}{l}\text { Virus glycoprotein } \\
\text { peptide (RVG29), } \\
\text { PEG }\end{array}$} & \multirow{4}{*}{$\begin{array}{l}\text { Rotenone- } \\
\text { induced PD } \\
\text { model rats }\end{array}$} & - Downregulated caspase-3 activity in brains & \multirow[t]{4}{*}{ [96] } \\
\hline & & & & - Improved locomotor activity in open field test & \\
\hline & & & & - Rescued TH-positive neurons & \\
\hline & & & & - Decreased the levels of TNF- $\alpha$ and NO & \\
\hline \multirow[t]{3}{*}{$\mathrm{C}_{60}(\mathrm{OH})_{24}$} & \multirow[t]{3}{*}{-} & \multirow[t]{3}{*}{-} & \multirow{3}{*}{$\begin{array}{l}\text { MPP+-induced } \\
\text { PD model cells }\end{array}$} & - Protected cells from oxidative damage & \multirow[t]{3}{*}{ [98] } \\
\hline & & & & $\begin{array}{l}\text { - Prevented against mitochondrial dysfunction, including } \\
\text { improvement of MMP and complex I and II activities }\end{array}$ & \\
\hline & & & & $\begin{array}{l}\text { - Increased total GSH levels, also prevented the total GSH loss and } \\
\text { enhanced [GSSG]/[GSHt] ratio significantly. And pretreatment with } \\
\mathrm{C}_{60}(\mathrm{OH})_{24} \text { did significantly inhibit the increase of [GSSG]/[GSHt] } \\
\text { ratio }\end{array}$ & \\
\hline $\begin{array}{l}\mathrm{CeO}_{2} \text { or ceria } \\
\text { nanoparticles or } \\
\text { nanoceria }\end{array}$ & - & - & $\begin{array}{l}\text { MPTP-induced } \\
\text { PD model mice }\end{array}$ & - Protected against the MPTP-induced decline in striatal dopamine & [99] \\
\hline \multirow{3}{*}{$\begin{array}{l}\text { Lactoferrin- } \\
\text { modified } \\
\text { nanoparticles }\end{array}$} & \multirow[t]{3}{*}{ Curcumin } & Lactoferrin & Rotenone- & - Efficiently reduced ROS levels & [100] \\
\hline & & & induced PD & - Significantly protected against rotenone-induced neurotoxicity & \\
\hline & & & & - Suppressed the expression of $\alpha$-synuclein & \\
\hline Nanocomposites & Curcumin & - & Drosophila of & - A significant delay of climbing ability lost & [101] \\
\hline & & & & - A significant decrease in the lipid peroxidation & \\
\hline $\begin{array}{l}\text { Resveratrol } \\
\text { nanoemulsion }\end{array}$ & $\begin{array}{l}\text { Vitamin E and } \\
\text { resveratrol }\end{array}$ & - & Wistar rats & - Significantly increased the levels of GSH and SOD & [103] \\
\hline $\begin{array}{l}\text { Polyanhydride } \\
\text { nanoparticles }\end{array}$ & Apocynin & Folic acid & $\begin{array}{l}\text { Dopaminergic } \\
\text { neuronal cell, } \\
\text { mouse primary } \\
\text { cortical neurons } \\
\text { and human } \\
\text { mesencephalic } \\
\text { cell }\end{array}$ & $\begin{array}{l}\text { - Protected against oxidative stress-induced mitochondrial } \\
\text { dysfunction more effectively }\end{array}$ & [107] \\
\hline PBCA nanoparticles & NGF & Polysorbate 80 & MPTP-induced & - Reversed the scopolamine-induced amnesia & [108] \\
\hline & & & PD model mice & - Increased locomotor activity & \\
\hline $\begin{array}{l}\text { 6-OHDA: 6-Hydroxyd } \\
\text { MPP+: 1-Methyl-4-ph } \\
\text { PD: Parkinson's diseas } \\
\text { Phosphatidylglycerol-k }\end{array}$ & $\begin{array}{l}\text { nine; GDNF: G } \\
\text { pyridinium; MP } \\
\text { G: Poly(ethylen } \\
\text { d phospholipid }\end{array}$ & 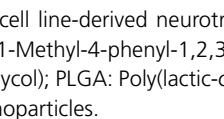 & , O-tetrany & $\begin{array}{l}\text { Glutathione; GSSG: Glutathione disulfide; MMP: Mitochondrial membr } \\
\text {; NO: Nitric oxide; PAMAM: Polyamidoamine; PBCA: Polymeric } n \text {-butyl-2- } \\
\text { Reactive oxygen species; SOD: Superoxide dismutase; TH: Tyrosine hydrox }\end{array}$ & $\begin{array}{l}\text { ential; } \\
\text { rylate; } \\
\text { P025: }\end{array}$ \\
\hline
\end{tabular}




\begin{tabular}{|c|c|c|c|c|c|}
\hline Nanomaterials & $\begin{array}{l}\text { Therapeutic } \\
\text { agent }\end{array}$ & Target ligand & Model & Outcome & Ref. \\
\hline \multirow[t]{4}{*}{ PAMAM dendrimer } & \multirow[t]{4}{*}{ GDNF gene } & \multirow[t]{4}{*}{ Lactoferrin and PEG } & \multirow{4}{*}{$\begin{array}{l}\text { Rotenone- } \\
\text { induced PD } \\
\text { rats } \\
6-\mathrm{OHDA}- \\
\text { induced PD } \\
\text { rats }\end{array}$} & - Markedly increased locomotor activity in rats & \multirow[t]{2}{*}{ [109] } \\
\hline & & & & - Rescued dopaminergic neurons & \\
\hline & & & & $\begin{array}{l}\text { - Lowered apomorphine-induced rotation and improved } \\
\text { locomotor activity }\end{array}$ & \multirow[t]{2}{*}{ [110] } \\
\hline & & & & - Reduced dopaminergic neuronal loss & \\
\hline
\end{tabular}

6-OHDA: 6-Hydroxydopamine; GDNF: Glial cell line-derived neurotrophic factor; FGSH: Glutathione; GSSG: Glutathione disulfide; MMP: Mitochondrial membrane potential; $\mathrm{MPP}^{+}$: 1-Methyl-4-phenylpyridinium; MPTP: 1-Methyl-4-phenyl-1,2,3,6-tetrahydropyridine; NO: Nitric oxide; PAMAM: Polyamidoamine; PBCA: Polymeric $n$-butyl-2-cyanoacrylate; PD: Parkinson's disease; PEG: Poly(ethylene glycol); PLGA: Poly(lactic-co-glycolic acid); ROS: Reactive oxygen species; SOD: Superoxide dismutase; TH: Tyrosine hydroxylase; VP025: Phosphatidylglycerol-based phospholipid nanoparticles.

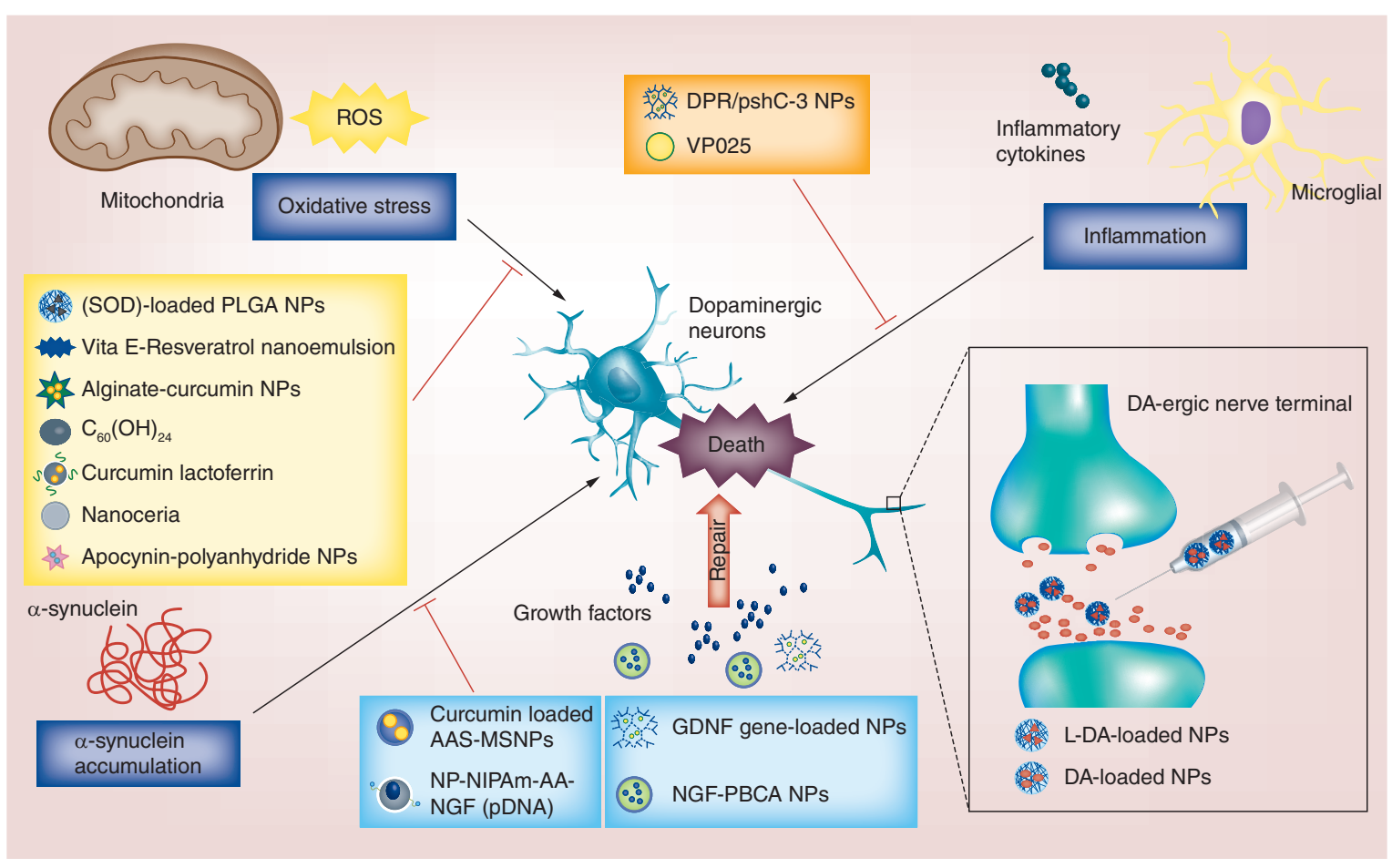

Figure 2. Schematic diagram of the nano-therapy strategies in Parkinson's disease.

DA: Dopamine; DPR: Dendrigraft; NP: Nanoparticle; PBCA: Polymeric n-butyl-2-cyanoacrylate; ROS: Reactive oxygen species.

therapeutic effects of nano-DOPA were estimated in PD model rats using motor coordination tests. Compared with levodopa or levodopa-benserazide (the peripheral decarboxylase inhibitor)-treated PD rats, nano-DOPA-treated $\mathrm{PD}$ rats exhibited longer-lasting therapeutic effects with a significant restoration of motor function. Further analysis demonstrated that nano-DOPA had a greater effective half-life, bioavailability and efficacy. These characteristics highlight the feasibility of applying nanotechnology to levodopa administration for PD treatment [85].

The fact that DA cannot cross the BBB is also a key limitation of directly treating PD with DA. Recently, NPs have been modified to deliver DA across the $\mathrm{BBB}$ and control its release. In fact, DA-loaded PLGA NPs were designed to deliver DA into the brains of 6-hydroxydopamine (6-OHDA)-induced PD model rats. Intravenous administration of DA-loaded PLGA NPs significantly increased DA levels in the SNC and recovered neurobehavioral abnormalities without cardiovascular toxicity in the brain or periphery. Furthermore, DA-loaded PLGA NPs slowly and continually released DA, potentially reducing DA autoxidation-mediated toxicity and avoiding drug-related side effects. In summary, DA-loaded PLGA NPs can deliver DA into the brain and prevent bulk DA-associated toxicity, suggesting that nanotechnology may provide a safe and novel therapeutic tool for DA supplementation strategies [86]. 
Targeting $\alpha$-synuclein accumulation

Neuroprotective therapy is believed to prevent neuronal cell death through inhibition of cell dysfunction and death-related molecular pathways. Among the various implicated molecular pathways, $\alpha$-synuclein accumulation has been considered a key contributor to neurodegeneration in PD. The conversion of $\alpha$-synuclein from soluble monomers to insoluble forms contributes to toxic consequences such as disruption of synaptic transmission, impairment of the UPS and mitochondrial dysfunction [87]. More recent evidence suggests that host $\alpha$-synuclein may exert deleterious effects on neighboring cells through self-propagating conformation [88]. Given the potential toxicity of various $\alpha$-synuclein aggregates (oligomers and fibrils), approaches targeting $\alpha$-synuclein accumulation could protect against neurodegeneration and revolutionize PD treatment [89]. In this way, NPs designed as nonviral vectors or $\alpha$-synuclein-targeting carriers offer great potential for inhibition of $\alpha$-synuclein production.

A recent study by Loureiro et al. [90] showed that double targeting immunoliposomes might have therapeutic potential by targeting $\alpha$-synuclein. In this study, immunoliposomes were decorated with the antitransferrin receptor OX26 (to target the BBB) and anti- $\alpha$-synuclein LB509 Abs (to target $\alpha$-synuclein). EGCG was used as the test drug, which was encapsulated in the immunoliposomes. This immunoliposome-encapsulated EGCG continuously released for $44 \mathrm{~h}$ in an in vitro BBB model [90]. Curcumin-loaded amine-functionalized mesoporous silica NPs have been reported to significantly inhibit $\alpha$-synuclein fibril formation [91]. It is conceivable that future PD therapy will focus on using these dual targeting immunoliposomes to deliver $\alpha$-synuclein aggregation and/or production inhibitors. More recently, magnetic $\mathrm{Fe}_{3} \mathrm{O}_{4} \mathrm{NPs}$ were designed as novel nanocarriers to reduce $\alpha$-synuclein expression. The nanocarriers were prepared from magnetic $\mathrm{Fe}_{3} \mathrm{O}_{4} \mathrm{NPs}$ and coated with $N$-isopropylacrylamide derivative (NIPAm-AA) and NGF. The shRNA was then loaded onto the $\mathrm{Fe}_{3} \mathrm{O}_{4}$ NPs (NP-NIPAm-AA-NGF [pDNA]). Amazingly, NP-NIPAm-AA-NGF (pDNA) successfully interfered with $\alpha$-synuclein synthesis in 1-methyl-4-phenyl1,2,3,6-tetrahydropyridine-induced PD model mice and sequentially prevented $\alpha$-synuclein-induced toxicity [92].

\section{Targeting inflammation}

Inflammation is recognized as a key contributor to PD. A number of studies have shown that microglia, inflammatory cytokines and the complement systems at least in part drive neuronal death in PD [93]. Therefore, anti-inflammatory agents may delay PD progression, attracting the attention of many investigators interested in designing NPs to target these inflammatory pathways.

VP025 has also been used in PD treatment. In fact, VP025 can prevent microglial activation and inhibit 6-OHDA-induced dopaminergic neuron loss. Moreover, VP025 can also prevent impairment of dopaminergic motor activity in 6-OHDA or proteasome inhibition-induced PD models [94,95]. Another study performed by Liu et al. [96] used dendrigraft poly-L-lysine NPs to encapsulate shRNAs to silence caspase-3, which consequently stopped microglial activation and prevented neuronal death. In this study, encapsulated caspase-3 shRNA (pshC-3) dendrigraft poly-L-lysine NPs (DPR/pshC-3 NPs) were modified with rabies virus glycoprotein peptide (RVG29) to cross the BBB. This DPR/pshC-3 NP downregulated the expression and activation of caspase-3, substantially improving locomotor activity and rescuing dopaminergic neuronal loss in PD model rats [96].

\section{Targeting antioxidative stress}

Studies conducted on human postmortem material suggest that reactive oxygen species (ROS) generated by mitochondrial complex I inhibition also play an important role in PD pathogenesis. Therefore, excessive ROS are likely to contribute to oxidative stress [97]. NPs have been widely explored to resist oxidative damage or target mitochondria for therapeutic purposes.

Recently, the polyhydroxylated fullerene derivative $\mathrm{C}_{60}(\mathrm{OH})_{24}$ was shown to prevent mitochondrial dysfunction and oxidative damage in 1-methyl-4-phenylpyridinium-induced neuroblastoma PD model cells. These studies confirmed that $\mathrm{C}_{60}(\mathrm{OH})_{24}$ not only worked as a powerful free radical scavenger but also as a Phase 2 enzyme inducer, consequently indirectly activating antioxidant pathways [98]. Nevertheless, $\mathrm{C}_{60}(\mathrm{OH})_{24}$ toxicity was still a big problem. It is also worth noting that nanoceria-based treatments have extended to PD due to a recent study showing that nanoceria protects against 1-methyl-4-phenyl-1,2,3,6-tetrahydropyridine-induced dopaminergic neurodegeneration in a PD mouse model [99].

As well as antioxidative nanostructures, NPs have also been used to deliver antioxidants to protect neurons. Recently, Bollimpelli et al. [100] demonstrated that curcumin-loaded lactoferrin NPs were effective for intracellular drug uptake, sustained retention and neuroprotection against rotenone-induced neurotoxicity in SK-N-SH cells [100]. Similarly, alginate-curcumin nanocomposite was reported to reduce oxidative stress and prevent neuronal apoptosis 
in a fly PD model. This nanocomposite showed a significant dose-dependent delay in climbing disability [101]. Another study showed that superoxide dismutase (SOD)-loaded PLGA NPs protected against $\mathrm{H}_{2} \mathrm{O}_{2}$-induced oxidative stress in cultured human neurons in a dose- and time-dependent manner [102]. Moreover, vitamin E-loaded resveratrol nanoemulsion reduced oxidative stress by increasing glutathione (GSH) and SOD levels in haloperidoltreated rats. Stable vitamin E nanoemulsion encapsulating resveratrol provided a higher targeting efficiency and reduced haloperidol-induced neuronal death [103]. These findings suggest that NP-modified agents have a potent antioxidative application potential for PD treatment.

Notably, mitochondrial dysfunction, which is believed to be relevant in PD pathogenesis, contributes to free radical stress and causes neuronal damage. Organelle-specific targeting NPs have emerged as a promising technology to restore mitochondrial dysfunction. A recent study demonstrated the feasibility of using peptide-based multiwalled carbon nanotubes to deliver nucleic acids to mitochondria [104], suggesting that NP-based intracellular delivery is a potential way to address mitochondrial dysfunction diseases. Furthermore, surface modification of nanocarriers with mitochondriotropic triphenylphosphonium cations facilitated efficient subcellular delivery and significantly enhanced the therapeutic effect and activity of ceramide [105]. Similarly, triphenylphosphonium-conjugated dendrimers have been used as polymeric gene vectors, showing high transfection efficacy with low cytotoxicity in HeLa and COS-7 cells [106]. Encouragingly, a recent study showed that apocynin (the mitochondria-targeting antioxidant)-loaded polyanhydride NPs protected against oxidative stress-induced neuronal damage in different cells [107]. These functional NPs have the potential for application in mitochondria dysfunction-related PD diagnosis and treatment.

\section{Neurotrophic factor supplementation}

NGF and other neurotrophic factors such as glial cell line-derived neurotrophic factor (GDNF) are essential to CNS development and function. NGF and GDNF effectively protect and repair degenerate neurons. However, the low BBB permeability of both NGF and GDNF limit translation to clinical practice. NPs have emerged as targeted carriers for the delivery of these therapeutic proteins or genes across the BBB.

An early study showed that PBCA NPs could deliver NGF into the brains of PD model mice. Polysorbate 80-coated PBCA NPs adsorbed NGF and transported it across the BBB. After intravenous administration, the NGF-adsorbed PBCA NPs successfully reversed scopolamine-induced amnesia and improved recognition and memory [108]. Another study reported that $G D N F$ gene-encapsulated lactoferrin-modified NPs exhibited powerful neuroprotection in 6-OHDA or rotenone-induced PD models. Indeed, this functionalized NP increased and maintained GDNF expression. As a result, improvements in locomotor activity, increased levels of monoamine neurotransmitters, and decreased dopaminergic neuronal loss were observed in both models $[109,110]$.

In conclusion, nanotechnology is increasingly being developed for PD therapy. Although considerable advances have been made in nanotechnology-based DA replacement and neuroprotective strategies, the gap between the laboratory and clinic still requires a lot of effort to be bridged. As such, there remains a need for further investigations in applying nanotechnology to these aforementioned neuroprotective strategies.

\section{Detection of PD biomarkers}

Early-stage diagnosis of PD is crucial for preventing disease progression. Preclinical-stage biomarkers could help to identify high-risk individuals and provide the opportunity to treat patients before motor and nonmotor symptoms develop [111]. $\alpha$-Synuclein and DA abnormalities and mitochondrial dysfunction are closely related to PD, but the highly sensitive detection of biomarkers related to these processes remains a challenge for current technologies. To solve this problem, a number of nanotechnology-based approaches have been developed to detect $\alpha$-synuclein, DA and mitochondrial dysfunction.

\section{a-Synuclein detection}

Ultrasensitive detection of $\alpha$-synuclein may be helpful in PD diagnosis, as $\alpha$-synuclein plays an important role in PD pathogenesis. An et al. [112] reported a novel, highly sensitive and stable electrochemical immunosensor prepared from G4-polyamidoamine dendrimer-encapsulated AuNPs (PAMAM-Au nanocomposites). The PAMAM-Au nanocomposite was constructed as an effective platform to target $\alpha$-synuclein and assist electron transfer for signal enhancement. Later, horseradish peroxidase secondary Ab was attached to AuNPs to achieve enzymatic signal amplification. In fact, this dual signal amplification technology reached a limit of detection of $14.6 \mathrm{pg} / \mathrm{ml}$ for $\alpha$-synuclein [112]. Another study developed a high-sensitivity immunosensor using $\mathrm{Au}$-doped $\mathrm{TiO}_{2}$ nanotube 
arrays for photoelectrochemical detection of $\alpha$-synuclein. This immunosensor was an effective platform for signal amplification that increased sensitivity to concentration limits of $34 \mathrm{pg} / \mathrm{ml}$ [113].

\section{$D A$ detection}

The preferential vulnerability of dopaminergic neurons in PD suggests that DA may play a major role in PD pathophysiology. Therefore, DA detection may be a feasible strategy for PD diagnosis. Nanotechnology-based DA detection is highly sensitive and could form the basis of early diagnostic tools for PD. Vertically aligned zinc oxide $(\mathrm{ZnO})$ nanowire arrays ( $\mathrm{ZnO}$ NWAs) prepared from a 3D graphene foam were a promising method to detect DA with high sensitivity. ZnO NWAs also demonstrated high selectivity, with a detection limit of $1 \mathrm{nM}$ for DA in the serum of PD patients. Furthermore, ZnO NWAs also selectively detected uric acid and ascorbic acid through a method called differential pulse voltammetry. Further comparison and analysis of uric acid levels in PD patients and healthy individuals suggested that uric acid may also be a biomarker for early PD [114].

\section{Detection of mitochondrial dysfunction}

As noted above, PD has always been linked to mitochondrial dysfunction. Ma et al. [115] developed an in vitro and intracellular complex I sensor-attaching ubiquinone-terminated disulfide ( $\mathrm{QnNS}$ ) to attach CdSe/ZnS quantum dots (QDs; QnNS-QDs). The complex showed the capacity for early detection and monitoring of PD. In the presence of NADH and complex I (the first enzyme of the mitochondrial respiratory chain), the surface-attached QnNS-QD layer was reduced to HQnNS-QDs by electron transfer. Since QDs are highly sensitive to changes in electron transfer, the change in QD fluorescence intensity reflected the level of complex I. As such, QnNS-QDs were feasible for detecting complex I levels in human SH-SY5Y neuroblastoma cells via monitoring of fluorescence changes. This technique may represent a promising tool for PD detection [115].

In summary, PD pathogenesis involves various molecular pathways, all of which contain potential biomarkers for early PD diagnosis. DA, $\alpha$-synuclein and mitochondrial dysfunction are all attractive targets for nanotechnologybased diagnostic approaches.

\section{Nanotechnology in stroke}

Stroke, one of the most common causes of human disability and death, is caused by the interruption of the blood supply in the brain to deprive tissue of oxygen and nutrients, leading to a cascade of pathological biochemical reactions and ultimately cell and tissue death. There are two types of stroke: ischemic and hemorrhagic. Ischemic stroke is more common, accounting for $87 \%$ of all stroke occurrences [116], and ischemic tissue is distinguished by a necrotic core surrounded by a variably sized ischemic penumbra. This is because cell death occurs in minutes due to a lack of ATP, ionic disruption and other dysfunction in the ischemic area, while in peripheral zones, termed the ischemic penumbra, neurons are potentially salvageable due to residual perfusion from collateral blood vessels [117]. Therefore, it is possible and necessary to limit neuronal injury and restore cellular function in the ischemic penumbra. Early recanalization by clot lysis and reperfusion can decrease ischemic injury. However, only a few patients (about $5 \%$ ) receive this therapy due to the short therapeutic time window (of about $3 \mathrm{~h}$ ) [118]. Other drawbacks of this traditional treatment include a risk of reperfusion damage, brain edema and hemorrhagic complications [119]. These drawbacks have prompted the development of alternatives such as thrombolysis and neuroprotective treatments, which include inhibition of oxidative stress, inflammation and apoptosis. Nanotechnology presents numerous advantages and opportunities in stroke treatment including enhanced BBB permeability and the capacity for sustained and controlled drug release. Most researches on nanotechnology-based therapeutics in stroke have focused on applying these advantages to preventing oxidative stress, inflammation and apoptosis (Figure $3 \&$ Table 3).

\section{Recanalization therapy}

Intravenous thrombolysis with recombinant tissue plasminogen activator (tPA) remains the standard clinical treatment for acute ischemic stroke patients within $4.5 \mathrm{~h}$ of symptom onset [120]. However, intravenous thrombolysis carries potential hemorrhagic complications. tPA, which activates plasmin so as to trigger fibrinolysis, is systemically distributed rather than specifically activating fibrinolysis. However, after stroke onset, the vascular flow slows due to the obstructed blood vessel, and higher doses of tPA are required for effective thrombolysis, aggravating hemorrhagic complications. Nanotechnology offers a convenient platform to immobilize and encapsulate specific molecules in nanocarriers at a higher loading rate. Thus, nanotechnology-based approaches can further reduce hemorrhagic complication rates by effectively delivering thrombolytic agents to the thrombus. Recent reports have suggested 


\begin{tabular}{|c|c|c|c|c|c|}
\hline Nanomaterials & $\begin{array}{l}\text { Therapeutic } \\
\text { agent }\end{array}$ & Target ligand & Model & Outcome & Ref. \\
\hline \multirow[t]{6}{*}{ Liposomes } & \multirow{2}{*}{\multicolumn{2}{|c|}{ Hemoglobin }} & \multirow{2}{*}{$\begin{array}{l}\text { Impermanent middle } \\
\text { carotid arteries } \\
\text { occlusion of monkey }\end{array}$} & $\begin{array}{l}\text { - The LEH-treated monkeys had a better mobilization and } \\
\text { muscular strength in the forelimb and in the hindlimb }\end{array}$ & [130] \\
\hline & & & & - The cortex morphological changes were prevented & [131] \\
\hline & \multirow{4}{*}{\multicolumn{2}{|c|}{ Quercetin }} & \multirow{4}{*}{$\begin{array}{l}\text { Permanent middle } \\
\text { cerebral artery } \\
\text { occlusion of rats }\end{array}$} & - Partial reversal of motor deficits & \multirow[t]{4}{*}{ [137] } \\
\hline & & & & $\begin{array}{l}\text { - Significantly prevented a reduction of GSH levels in ipsilateral } \\
\text { striatum and cortex }\end{array}$ & \\
\hline & & & & $\begin{array}{l}\text { - A significant increase in numbers of neuron cells in striatum and } \\
\text { cortex }\end{array}$ & \\
\hline & & & & - Significantly reduced cerebral oedema volume & \\
\hline \multirow[t]{5}{*}{ PLGA nanoparticles } & \multirow[t]{5}{*}{-} & & \multirow{5}{*}{$\begin{array}{l}\text { Impermanent common } \\
\text { carotid arteries } \\
\text { occlusion of rats }\end{array}$} & - Prevented degradation of SOD and catalase from ischemic insults & \multirow[t]{5}{*}{ [138] } \\
\hline & & & & - Markedly reduced ROS generation & \\
\hline & & & & $\begin{array}{l}\text { - Significantly downregulated the expression of iNOS in the } \\
\text { hippocampus }\end{array}$ & \\
\hline & & & & - Minimized the caspase-3 activity in hippocampal region & \\
\hline & & & & $\begin{array}{l}\text { - It is predicted to be highly effective in preventing hippocampal } \\
\text { neuronal loss }\end{array}$ & \\
\hline \multirow{2}{*}{$\begin{array}{l}\text { Polylactide } \\
\text { nanoparticles }\end{array}$} & \multirow[t]{2}{*}{-} & & & - GSSG/GSH ratio was significantly reduced & \multirow[t]{2}{*}{ [139] } \\
\hline & & & & - Markedly reduced diene generation in whole brain homogenate & \\
\hline \multirow{3}{*}{$\begin{array}{l}\text { Solid lipid } \\
\text { nanoparticles }\end{array}$} & \multirow{3}{*}{\multicolumn{2}{|c|}{ Curcumin }} & \multirow{3}{*}{$\begin{array}{l}\text { Bilateral common } \\
\text { carotid arteries } \\
\text { occlusion of rats }\end{array}$} & - Significantly attenuated the increase in ITL and RTL in the EPM & \multirow[t]{3}{*}{ [140] } \\
\hline & & & & $\begin{array}{l}\text { - A significant improvement in memory consolidation in Morris } \\
\text { water maze }\end{array}$ & \\
\hline & & & & - Significantly restored the LPO, GSH, SOD, catalase and nitrite & \\
\hline \multirow{2}{*}{$\begin{array}{l}\text { Polymer } \\
\text { (PEG-polystyrene) } \\
\text { nanoparticles }\end{array}$} & \multirow{2}{*}{\multicolumn{2}{|c|}{$\begin{array}{l}\text { Antioxidant } \\
\text { nitroxyl radicals } \\
\text { such as TEMPO }\end{array}$}} & \multirow{2}{*}{$\begin{array}{l}\text { Impermanent middle } \\
\text { carotid arteries } \\
\text { occlusion of rats }\end{array}$} & $\begin{array}{l}\text { - Significantly lowered superoxide anions production in neuronal } \\
\text { cells }\end{array}$ & \multirow[t]{2}{*}{ [141] } \\
\hline & & & & - Reduced the infarction volume significantly & \\
\hline \multirow[t]{4}{*}{ PLGA nanoparticles } & \multirow{4}{*}{\multicolumn{2}{|c|}{ SOD }} & \multirow{4}{*}{$\begin{array}{l}\text { Focal cerebral } \\
\text { ischemia-reperfusion } \\
\text { injury model }\end{array}$} & - Significantly lowered neurological-deficit scores & \multirow[t]{4}{*}{ [142] } \\
\hline & & & & $\begin{array}{l}\text { - The infarct lesion area in each coronal slice of brain was } \\
\text { significantly less }\end{array}$ & \\
\hline & & & & - The number of TUNEL-positive cells was significantly fewer & \\
\hline & & & & - Significantly reduced the ROS activation & \\
\hline Liposomes & SOD & PEG & \multirow{3}{*}{$\begin{array}{l}\text { Mouse model of } \\
\text { cerebral ischemia and } \\
\text { reperfusion injury }\end{array}$} & \multirow{3}{*}{$\begin{array}{l}\text { - Got an appreciably better improvement in neurological behavior } \\
\text { test } \\
\text { - Significantly decreased the infarct volume }\end{array}$} & [143] \\
\hline PBCA nanoparticles & SOD & Anti-NR1 & & & \\
\hline PLGA nanoparticles & SOD & antıbody & & & \\
\hline $\begin{array}{l}\mathrm{CeO}_{2} \text { or ceria } \\
\text { nanoparticles or }\end{array}$ & - & & $\begin{array}{l}\text { Mouse hippocampal } \\
\text { brain slice model of }\end{array}$ & $\begin{array}{l}\text { - Decreased ischemia-induced ROS production by approximately } \\
30 \%\end{array}$ & [145] \\
\hline nanocerıa & & & Ischemıa & - Reduced ischemic cell death by approximately $50 \%$ & \\
\hline & & & & - Reduced ROS levels & \\
\hline & & & & - Significantly increased cell viability & \\
\hline & & & $\begin{array}{l}\text { CHO-K1 cells incubated } \\
\text { to increase intracellular } \\
\text { ROS }\end{array}$ & - Protected CHO-K1 cells from ROS-induced cell death & {$[146]$} \\
\hline & & & Ischemic stroke model & - Considerably reduced infarct volumes up to $50 \%$ & \\
\hline & & & & $\begin{array}{l}\text { - Lowered the number of apoptotic cells and decreased } \\
\text { proapoptotic proteins, such as phospho-p53, cleaved caspase-3 and } \\
\text { gelsolin }\end{array}$ & \\
\hline $\begin{array}{l}\text { Polymer } \\
\text { (e-caprolactone) }\end{array}$ & Indomethacin & & $\begin{array}{l}\text { OGD model of } \\
\text { hippocampal slice }\end{array}$ & $\begin{array}{l}\text { - Significantly prevented the increase of IL-1b, IL- } 6 \text { and TNF- } \alpha \text { levels } \\
\text { in the culture medium }\end{array}$ & [151] \\
\hline nanoparticles & & & cultures & $\begin{array}{l}\text { - Significantly reduced the phosphorylation levels of ERK } 1 / 2 \text { and } \\
\text { JNK }\end{array}$ & \\
\hline & & & & - Prevented the OGD-induced IB4 reactivity & \\
\hline & & & & - Cell death significantly decreased & \\
\hline $\begin{array}{l}\text { Anti-NR1 antibody: An } \\
\text { Glutathione disulfide; } \\
\text { Liposome-encapsulate } \\
\text { Polymeric n-butyl-2-cy } \\
\text { oxygen species; RTL: R } \\
\text { nickend labeling; Z-DE }\end{array}$ & $\begin{array}{l}\text { VMDA (N-methy } \\
\text { GB 1: High mobi } \\
\text { emoglobin; LPO }\end{array}$ & partate) rece & $\begin{array}{l}\text { tor } 1 \text { antibody; EPM: Eleval } \\
\text { Isolectin B4; iNOS: Inducib } \\
\text { NMDA: N-methyl-D-aspar } \\
\text { PLGA: Poly(lactic-co-glycc }\end{array}$ & $\begin{array}{l}\text { ed plus maze; ERK: The extracellular-signal-regulated kinase; GSH: Glutathio } \\
\text { e nitric oxide synthase; ITL: Initial transfer latency; JNK: The c-Jun N-terminal ki } \\
\text { ic acid receptor; OGD: Oxygen-glucose deprivation; PAMAM: Polyamidoami } \\
\text { ic acid); PX-18: 2-N, N-bis(oleoyloxyethyl) amino-1-ethanesulfonic acid; ROS } \\
\text { 2,6,6-Tetramethylpiperidine-1-oxyl; TUNEL: Terminal deoxynucleotidyl transfe } \\
\text { fluoromethyl ketone; TfRMAb: Antimouse transferrin receptor monoclonal a }\end{array}$ & $\begin{array}{l}\text { SG: } \\
\text { EH: } \\
\text { CA: } \\
\text { tive } \\
\text { UTP }\end{array}$ \\
\hline
\end{tabular}




\begin{tabular}{|c|c|c|c|c|c|}
\hline Nanomaterials & $\begin{array}{l}\text { Therapeutic } \\
\text { agent }\end{array}$ & Target ligand & Model & Outcome & Ref. \\
\hline \multirow[t]{4}{*}{ PX-18 nanocrystals } & \multirow{4}{*}{\multicolumn{2}{|c|}{ PX-18 }} & \multirow{4}{*}{$\begin{array}{l}\text { Impermanent common } \\
\text { carotid arteries } \\
\text { occlusion of gerbils }\end{array}$} & $\begin{array}{l}\text { - Markedly decreased reactive astrocytes and reduced microglial } \\
\text { activation }\end{array}$ & \multirow[t]{4}{*}{ [152] } \\
\hline & & & & - Significantly reduced neuronal DNA damage & \\
\hline & & & & - Resulted in a marked reduction of delayed neuronal death & \\
\hline & & & & - Reduced ischemia-induced neuronal degeneration & \\
\hline \multirow[t]{2}{*}{ PAMAM dendrimer } & \multirow{2}{*}{\multicolumn{2}{|c|}{ HMGB1 SiRNA }} & \multirow{2}{*}{$\begin{array}{l}\mathrm{H}_{2} \mathrm{O}_{2} \text { - or } \\
\text { NMDA-treated primary } \\
\text { cortical culture }\end{array}$} & $\begin{array}{l}\text {-Alleviated NMDA-induced neuronal death in primary cortical } \\
\text { culture }\end{array}$ & \multirow[t]{2}{*}{ [153] } \\
\hline & & & & - Total infarction volume was reduced to $70.6 \%$ & \\
\hline \multirow{3}{*}{$\begin{array}{l}\text { Chitosan } \\
\text { nanospheres }\end{array}$} & \multirow[t]{3}{*}{ Z-DEVD-FMK } & \multirow[t]{3}{*}{ TfRMAb } & \multirow{3}{*}{$\begin{array}{l}\text { Focal cerebral } \\
\text { ischemia-reperfusion } \\
\text { injury model mice }\end{array}$} & - Significantly decreased the infarct volume & \multirow[t]{3}{*}{ [156] } \\
\hline & & & & - Decreased neurological deficits & \\
\hline & & & & $\begin{array}{l}\text { - Dramatically suppressed caspase-3 activities in the ischemic } \\
\text { hemispheres }\end{array}$ & \\
\hline \multirow[t]{2}{*}{ Carbon nanotubes } & \multirow{2}{*}{\multicolumn{2}{|c|}{ Caspase-3 siRNA }} & \multirow{2}{*}{$\begin{array}{l}\text { Endothelin Stroke } \\
\text { Model }\end{array}$} & - Significant reduction in the number of apoptotic cells & \multirow[t]{2}{*}{ [157] } \\
\hline & & & & - Significant improvement in the 'skilled reaching' tests & \\
\hline \multicolumn{6}{|c|}{$\begin{array}{l}\text { Anti-NR1 antibody: Anti-NMDA (N-methyl-D-aspartate) receptor } 1 \text { antibody; EPM: Elevalted plus maze; ERK: The extracellular-signal-regulated kinase; GSH: Glutathione; GSSG: } \\
\text { Glutathione disulfide; HMGB 1: High mobility group box 1; IB4: Isolectin B4; iNOS: Inducible nitric oxide synthase; ITL: Initial transfer latency; JNK: The c-Jun N-terminal kinase; LEH: } \\
\text { Liposome-encapsulated hemoglobin; LPO: Lipid peroxidation; NMDA: N-methyl-D-aspartic acid receptor; OGD: Oxygen-glucose deprivation; PAMAM: Polyamidoamine; PBCA: } \\
\text { Polymeric n-butyl-2-cyanoacrylate; PEG: Poly(ethylene glycol); PLGA: Poly(lactic-Co-glycolic acid); PX-18: 2-N,N-bis(oleoyloxyethyl) amino-1-ethanesulfonic acid; ROS: Reactive } \\
\text { oxygen species; RTL: Retention transfer latency; SOD: Superoxide dismutase; TEMPO: 2,2,6,6-Tetramethylpiperidine-1-oxyl; TUNEL: Terminal deoxynucleotidyl transferase dUTP } \\
\text { nickend labeling; Z-DEVD-FMK: N-benzyloxycarbonyl-Asp(OMe)-Glu(OMe)-Val-Asp(OMe)-fluoromethyl ketone; TfRMAb: Antimouse transferrin receptor monoclonal antibody. }\end{array}$} \\
\hline
\end{tabular}

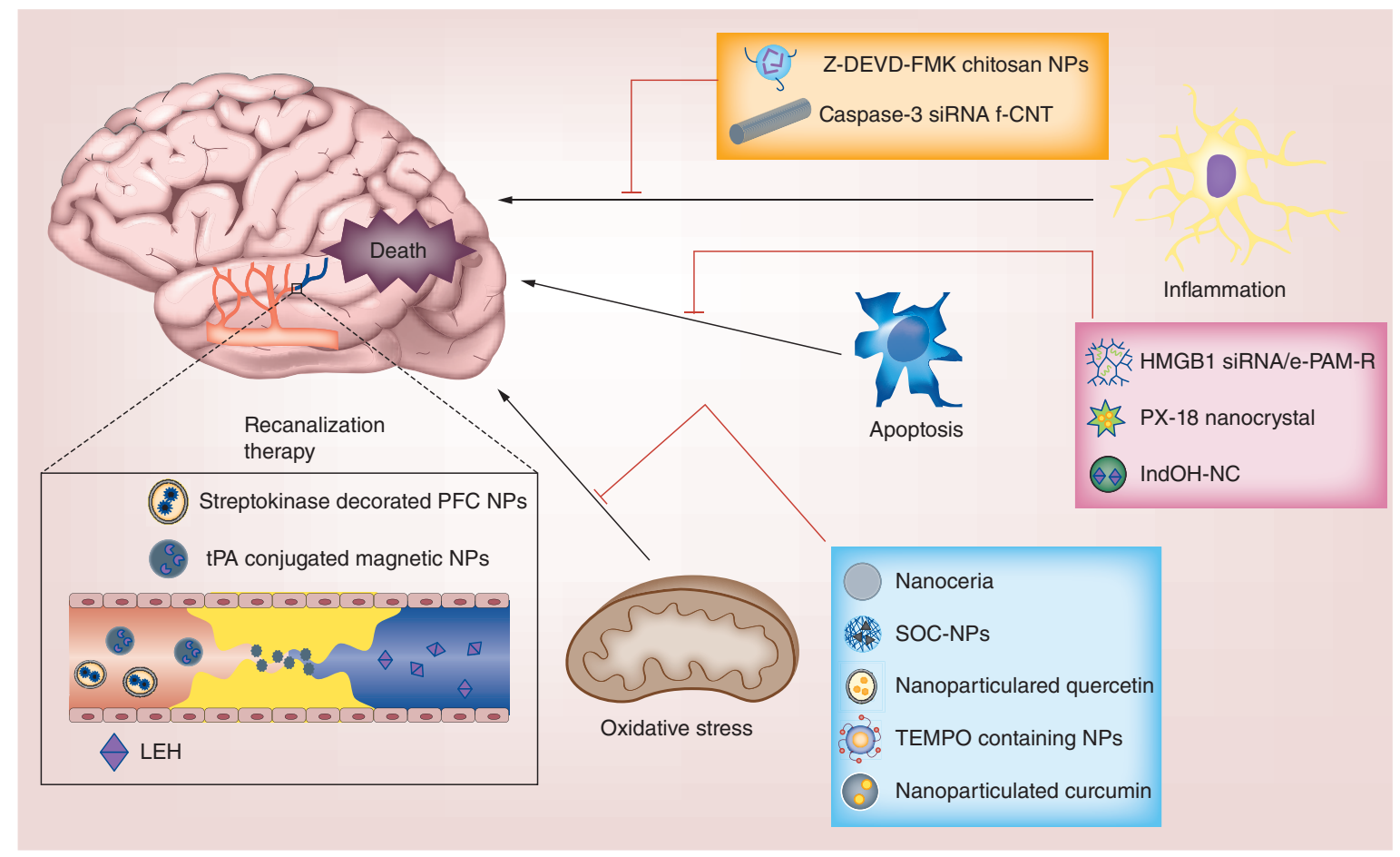

Figure 3. Schematic diagram of the nano-therapy strategies combating cell death instroke. NPs: Nanoparticles.

that MNPs based on superparamagnetic iron oxide are a promising candidate as a modified nanocarrier for targeted delivery of tPA [121-124]. For example, Chen et al. [122] found that silica-coated MNPs conjugated with $\mathrm{tPA}\left(\mathrm{SiO}_{2}-\right.$ MNP-tPA) enhanced storage stability. In a thrombolysis model, $\mathrm{SiO}_{2}$-MNP-tPA showed enhanced penetration into blood clots and significant reductions in blood clot lysis time under magnetic guidance compared with free tPA at the same drug dosage [122]. Encouragingly, a novel, magnetic-active nanomotor directly enhanced tPA-mediated thrombolysis and had a higher thrombus removal efficiency. This magnetic-active nanomotor not only targeted 
tPA to thrombus, but also effectively improved thrombolysis by improving drug delivery through control of many parameters such as nanorod concentration, magnetic field and frequency [125]. This innovative approach may provide new avenues for tPA-based stroke treatment.

Besides tPA, other thrombolytic agents such as streptokinase and urokinase have also been effective in animal clot models [126,127]. For example, perfluorocarbon (PFC) NPs, also known as artificial blood substitutes, have been decorated with antifibrin MAbs and urokinase. The decorated PFC NPs were highly selective in dissolving fibrin both in vitro and in a canine clot model [126]. Moreover, when decorated with streptokinase for specific fibrin targeting, PFC NPs showed the potential not only for clot detection and rapid induction of fibrinolysis but also for decreasing clot volume by approximately $30 \%$ over an hour [127]. Furthermore, McCarthy et al. [128] synthesized cross-linked dextran-coated iron oxide NPs (CLIO) to target two different thrombus components: activated factor XIII (FXIIIa, which can stabilize the nascent thrombus) and fibrin. In the study, FXIIIa-targeted CLIO was conjugated to recombinant tPA (CLIO-FXIII-PEG-tPA) to investigate its thrombolysis effects in a murine pulmonary embolism model. CLIO-FXIII-PEG-tPA efficiently bound to and readily lysed clots [128]. These results suggest that nanotechnology-based thrombolysis is a reasonable option for recanalization of occluded vessels, as bleeding and clot lysis complications may be avoided.

Narrow therapeutic time windows and other unintended risks are also limiting factors for the application of thrombolysis [129]. Nanotechnology-based oxygen carriers are good candidates for improving oxygen supply without the hemorrhagic risk. Liposome-encapsulated hemoglobin (LEH) possesses similar functions and structure to red blood cells and has been widely applied to protect cells from death and to reduce ischemic injury. For instance, Kawaguchi et al. [130] showed that LEH preserved the cerebral metabolic rate of $\mathrm{O}_{2}$ and significantly reduced the area of infarction in a monkey acute ischemic stroke model [130]. Longitudinal observations also confirmed that LEH could preserve cerebral metabolic rate of $\mathrm{O}_{2}$ for 8 days after occlusion and reperfusion of the middle cerebral artery in monkeys [131]. Recently, LEH was studied in a permanent middle cerebral artery occlusion model and was found to decrease cerebral infarct volumes as expected. Thereby, optimal results with LEH provided the exciting prospect of LEH translating into clinical use [132].

Despite successful recanalization after thrombolysis, reperfusion after prolonged ischemia is possibly deleterious due to ischemia-reperfusion injury [133]. However, Shimbo et al. [134] recently reported that infarct areas decreased and edema volumes in rat brains shrank after injection of LEH. Interestingly, LEH-treated mice performed better neurologically. These studies suggest that intraarterial infusion of LEH can potentially also reduce ischemiareperfusion injury [134].

\section{Targeting oxidative stress}

Many mechanisms lead to cell and tissue death in stroke including excitotoxicity, oxidative stress, inflammation and activation of apoptosis. Of these, oxidative stress generates numerous free radicals and plays an important role in ischemic damage. Free radicals including ROS and RNS react with nucleic acids, proteins and lipids and directly or indirectly lead to dysfunction before culminating in cell death [135]. Nanotechnology provides novel tools superior to current therapy for targeting oxidative stress in ischemic stroke.

Under normal physiological conditions, ROS are kept at low levels due to the scavenging mechanisms of endogenous antioxidant systems including SOD, GSH peroxidase, catalase and antioxidant vitamins. After reperfusion, several ROS-generating enzymatic systems are activated, and excessive ROS overwhelm endogenous antioxidant systems, leading to oxidative damage. Nanotechnology-based delivery of exogenous free radical scavengers to protect endogenous antioxidant enzymatic systems may be a reasonable and effective approach for ischemic stroke therapy.

Quercetin, an important polyphenolic bioflavonoid antioxidant, has the potential to be a strong free radical scavenger in oxidative stress-induced damage [136]. However, quercetin use in CNS diseases treatment is limited by the fact that it cannot cross the BBB. Liposomal quercetin (LQ) has shown excellent performance in a rat permanent ischemic stroke model. LQ reversed decreases in GSH within $24 \mathrm{~h}$ and alleviated cerebral edema, suggesting that LQ can protect against oxidative damage [137]. Furthermore, Das and colleagues [138] studied the neuroprotective effects of nanocapsule-encapsulated quercetin in a rat cerebral ischemia-reperfusion model, showing that nanoencapsulated quercetin could improve neuronal count, protect mitochondrial membranes and downregulate the activity of caspase- 3 and inducible nitric oxide synthase (iNOS), which produces nitric oxide to damage the brain and contributes to the late stages of cerebral ischemia, in both young and aged rat brains [138]. Moreover, further studies confirmed that these neuroprotective effects were achieved by protecting endogenous antioxidant enzymes such as SOD and catalase from ischemia-induced oxidative damage $[138,139]$. Curcumin has 
also been used to protect endogenous antioxidant enzymes, with Kakkar et al. [140] demonstrating that curcuminloaded solid lipid NPs restored SOD, GSH, catalase and mitochondrial complex enzyme levels in a mouse cerebral ischemic reperfusion injury model, indicating that curcumin-loaded solid lipid NPs may contribute to inhibition of lipid peroxidation and increase the activity of many endogenous antioxidant defense enzymes [140]. Recently, Marushima et al. [141] developed an antioxidant nitroxyl radical, 2,2,6,6-tetramethylpiperidine-1-oxyl (TEMPO), for inclusion in radical-containing NPs (RNPs) for scavenging free radicals. In an ischemia-reperfusion injury model, the infarction volumes of RNP-treated rat brains were significantly lower than controls. Moreover, both lipid peroxidation and protein oxidation were suppressed, indicating that RNPs have higher neuroprotective efficacy than conventional free-radical scavengers such as TEMPO [141].

As a major antioxidant, SOD is overconsumed in ischemic brains. Supplementing brains with exogenous SOD is an effective therapeutic strategy. Reddy and Labhasetwar [142] showed that SOD encapsulated in PLGA NPs (SODNPs) prevented neural edema, reduce ROS levels and protected neurons from apoptosis in the rat focal cerebral ischemia-reperfusion injury model. After SOD-NP administration, the neurological deficits of the treated rats were restored and their cerebral infarct areas shrank [142]. Furthermore, several NPs (liposomes, polybutylcyanoacrylate or PLGA) were synthesized to transfer the active form of SOD (4000 to 20,000 U/kg) in mouse cerebral ischemia and reperfusion injury models. All these designed NPs exhibited highly efficient reductions in infarct volume and improvements in behavioral tests (neurologic deficits) after cerebral ischemic injury. These distinct functional NPs were further confirmed to be effective in reducing apoptosis and inflammatory markers [143].

As well as transporting natural antioxidants or antioxidant enzymes, some NPs can directly scavenge free radicals because of their intrinsic antioxidant properties. For example, nanoceria, widely explored in chronic inflammation and degenerative diseases [53], have potent free radical-scavenging properties and good biocompatibility [144]. For ischemic stroke therapy, Estevez et al. [145] explored nanoceria in a mouse hippocampal ischemic brain slice model. The results revealed that nanoceria could reduce cell death by decreasing ROS and nitric oxide [145]. Similar results were found when nanoceria was applied to a rat focal ischemia-reperfusion model, reducing infarct volume, preventing ischemic cell death and significantly scavenging ROS. Notably, optimal doses of nanoceria ( 0.5 and $0.7 \mathrm{mg} / \mathrm{kg}$ ) were also reported [146]. These encouraging results suggest that nanoceria offer a hopeful treatment modality for ischemic stroke patients. Furthermore, water-soluble fullerene derivatives such as hexasulfonated $\mathrm{C}_{60}\left(\mathrm{FC}_{4} \mathrm{~S}\right)$ [147] and carboxyfullerene [148] were also functionalized to prevent oxidative damage. For instance, carboxyfullerene may attenuate oxidative injury in a transient focal ischemia-reperfusion rat model. In this study, intracerebroventricular infusion of carboxyfullerene not only decreased cortical infarction but also prevented the elevation of lipid peroxidation and GSH depletion. However, intravenous administration of carboxyfullerene did not protect against cortical infarction. Also, the undesirable effects of the treatment may limit the therapeutic utility of carboxyfullerene [148].

\section{Targeting inflammation}

Numerous studies indicate that cerebral ischemia induces the expression of a variety of inflammatory signaling factors [149]. These inflammatory molecules activate microglia and stimulate infiltration of peripheral leukocytes, which accelerates and expands the infarct [150]. Thus, inflammatory mediators such as cytokines, adhesion molecules and integrin are vital for initiating and sustaining neuroinflammation. These neuroinflammatory factors are produced immediately after the onset of ischemia and contribute to amplification of ischemic damage [117]. Therefore, blocking inflammatory responses to reduce damage is a promising neuroprotective therapeutic strategy.

Indomethacin, a nonsteroidal anti-inflammatory drug, was loaded into polymeric (polycaprolactone) NPs (IndOH-NC) and its neuroprotective effects evaluated on oxygen-glucose-deprived hippocampal slices. IndOHNC decreased levels of proinflammatory cytokines such as IL-1 $\beta$, IL- 6 and TNF- $\alpha$ for up to 48 h after oxygenglucose deprivation. Furthermore, phosphorylation of ERK1/2 and JNK was decreased, and iNOS expression also decreased [151]. Recently, a nanocrystal formulation of 2-N, N-bis (oleoyloxyethyl) amino-1-ethanesulfonic acid (PX-18) was reported to protect against cerebral ischemia-reperfusion-induced damage by inhibiting inflammation in gerbils. PX-18 is a selective inhibitor of the group IIA secretory phospholipase A2, which plays an important role in inflammatory processes. A PX-18 nanocrystal suspension offered good bioavailability, reduced delayed neuronal death and ameliorated DNA damage effectively in a gerbil ischemia-reperfusion model. Furthermore, glial cell activation was reduced, reinforcing the outstanding anti-inflammatory efficiency of PX-18 nanocrystals [152].

Another approach for anti-inflammation therapy is RNAi. Kim et al. [153] utilized biodegradable polyamidoamine ester (e-PAM-R) dendrimers to deliver siRNA of high mobility group box-1 (HMGB1, a novel cytokine-like 
molecule) into $\mathrm{H}_{2} \mathrm{O}_{2}$ - or NMDA-treated primary cortical cultures and rats with cerebral ischemia. The results revealed that transfection of $H M G B 1$ siRNA with e-PAM-R substantially alleviated $\mathrm{H}_{2} \mathrm{O}_{2}$ - or NMDA-induced neuronal death in cell cultures and rat brains. The transfection of $H M G B 1$ siRNA with e-PAM-R precisely suppressed gene expression associated with inflammation and markedly reduced infarct volumes, suggesting nanotechnologybased siRNA delivery holds potential for ischemia treatment [153].

\section{Targeting apoptosis}

After the onset of ischemic stroke, many neurons in the ischemic penumbra undergo apoptosis during acute and/or chronic phases due to tissue and cell damage triggering apoptotic pathways [154]. Apoptosis is believed to be responsible for the damage surrounding the core of the ischemic zone [155]. Hence, antiapoptotic therapy in ischemic stroke has been widely investigated. Caspase-3 has a vital role in apoptosis and is present in both the acute and chronic stages of ischemic stroke [154]. Application of $N$-benzyloxycarbonyl-Asp (OMe)-Glu (OMe)Val-Asp (OMe)-fluoromethyl ketone (Z-DEVD-FMK), a specific caspase-3 inhibitor, provided neuroprotection in ischemic stroke. To increase BBB permeability, Z-DEVD-FMK was loaded into chitosan nanospheres and conjugated to an antimouse transferrin receptor MAb to selectively recognize the transferrin receptor expressed on the cerebral vasculature. Z-DEVD-FMK-loaded nanospheres significantly decreased infarct volume, recovered neurological deficits and inhibited ischemia-induced caspase-3 activity in a mouse model [156]. Furthermore, RNAi technology has also been applied to caspase-3 inhibition. Al-Jamal et al. [157] found that caspase-3 siRNA delivered by functionalized carbon nanotubes significantly silenced caspase- 3 expression in neuronal tissue and reduced neurodegeneration in an endothelin-1-induced rodent stroke model. Notably, caspase-3 siRNA delivered by functionalized carbon nanotubes also promoted functional preservation before and after focal ischemic damage of the rodent motor cortex [157].

In summary, an ideal stroke therapeutic would benefit both primary and secondary neuronal damage. Theoretically, combination therapy that includes early relief from ischemia-hypoxia and persistent neuroprotection would be most beneficial for expanding the therapeutic window, minimizing side effects and ameliorating ischemiaand reperfusion-induced damage. In recent decades, nanotechnology has contributed to stroke treatment. Compared with traditional treatments, these developments have great potential to bridge the gap between experimental results and clinical outcomes. Especially, as ischemic stroke is also a thrombotic disease, the development of nanotechnology-based thrombolysis may also be applied to stroke treatment.

\section{Diagnosis of stroke}

Nanotechnology has also been explored for the diagnosis of ischemic stroke. There are two main nanotechnologybased diagnostic areas: imaging molecules as contrast agents and the detection of thrombosis biomarkers. Imaging molecules can improve early lesion detection, contributing to treatment monitoring and dose optimization [158]. An increasing number of reports suggest that nanotechnology-based molecular imaging can provide enhanced binding affinity, specificity and targeting efficacy. PFC NPs are synthetic organic compounds in which hydrogen atoms are replaced with fluorine atoms. They serve as a 'positive' contrast agent for the detection of inflammation by MRI. PFC NPs can be used to differentiate inflamed regions from healthy ones [159]. With respect to the detection of thrombosis biomarkers, thrombin-coated NPs may allow application in point-of-care diagnostics. Lin et al. [160] conjugated thrombin-sensitive peptide substrates to the surface of NPs to detect the changes in circulating thrombin levels, providing a novel system for sustained monitoring of coagulation [160].

\section{Nanotechnology in neurogenesis}

Neurogenesis refers to the processes by which neurons are generated from neural stem/precursor cells (NSPCs). Research over the past few decades has established that adult neurogenesis continuously occurs in specific regions of adult brains, primarily in the subventricular zone (SVZ) of the lateral ventricle and the subgranular zone of the hippocampal dentate gyrus $[161,162]$. The discovery of adult neurogenesis implies that lost neurons may be replaced by new ones, thus raising hope for restoring age- or disease-induced neuronal death and neurological function [163]. AD, PD and stroke commonly and progressively lose neuron structure or function. Under these conditions, neurogenesis is impaired or altered and its associated functions are compromised or lost $[164,165]$. As such, enhancing neuroregeneration may have the promising therapeutic potential for $\mathrm{AD}, \mathrm{PD}$ and stroke. Several groups have succeeded in stimulating endogenous neurogenesis and triggering NSPC differentiation using pharmacological agents, but the results from these studies have failed to translate to the clinical setting [166]. Obstacles include drug 


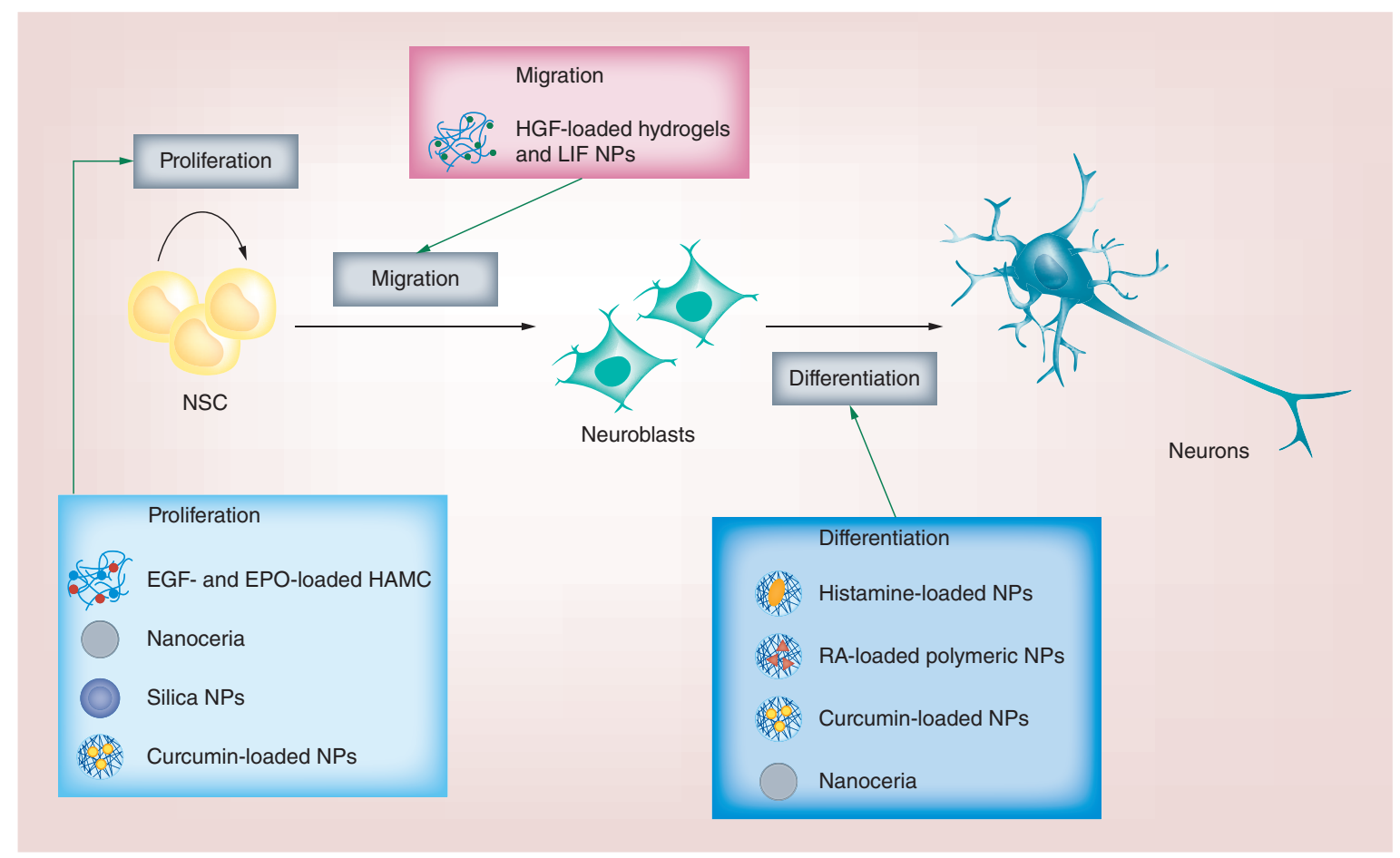

Figure 4. Schematic diagram of nanomaterials boost neurogenesis.

EPO: Erythropoietin; LIF: Leukemia inhibitory factor; NP: Nanoparticle; NSC; Neural stem cell; RA: Retinoic acid.

solubility, stability, BBB permeability and insufficient concentrations in damaged regions. Novel technologies are required to overcome these barriers and minimize undesirable effects. Therefore, nanotechnology has been studied to maximize BBB permeability for drug delivery, achieve sustained drug release and deliver multiple targets for restoring endogenous neurogenesis (Figure $4 \&$ Table 4).

Several growth factors such as erythropoietin (EPO), EGF, NGF, BDNF and FGF-2 have been identified that stimulate neurogenesis [167]. Wang et al. [168] engineered polymeric NPs containing EGF (which stimulates NSPC proliferation) or EPO (which reduces apoptosis of newly generated cells). The two functional NPs were encapsulated in a hyaluronan methylcellulose hydrogel (used for sustained release). This delivery system achieved the sequential release and accumulation of EGF followed by EPO: EGF was completely released within the first week, while EPO was released after the first week. The sustained release NPs promoted the regeneration in the peri-infarct region, which correlated with an increase in NSPC proliferation [168]. Besides delivery of growth factors, regulating distinct signaling pathways involved in NSPC survival and proliferation may also be effective. Nanoceria has been reported to promote neurogenesis by regulating AMPK-PKC-CBP (the 5'-adenine monophosphate-activated protein kinaseprotein kinase $\mathrm{C}$-cyclic adenosine monophosphate response element-binding protein) signaling pathway, thereby bringing about multiple benefits in ND therapy [169]. Nanoceria has been well studied in antioxidative stress [170]. In a recent report, PEG-coated nanoceria significantly reduced oxidative stress under hypoxia exposure, promoted neurogenesis and enhanced hippocampal neuron survival. Correspondingly, Morris water maze tests revealed that coated nanoceria ameliorated hypoxia-induced memory impairment in a rat model [169]. The canonical Wnt/ $\beta$ catenin signaling pathway is mainly involved with survival, proliferation and differentiation of NSPCs during adult hippocampus neurogenesis $[171,172]$ and is likely to play a significant role in the pathophysiology of many NDs and act as a potential target in regenerative or neuroprotective therapy [173]. It is well known that glycogen synthase kinase-3 $\beta$ (GSK-3 $\beta$ ) inhibition can activate Wnt/ $\beta$-catenin signaling by enhancing $\beta$-catenin levels [174]. Thus, intracellular delivery of specific GSK-3 $\beta$ inhibiting proteins is a direct way to regulate neurogenesis. However, few of these proteins can be delivered into the cytoplasm due to the impermeable cell membrane. Hydrophobically modified 15-nm silica NPs attached to GFP-FRAT tide (green fluorescent protein, frequently rearranged in advanced T-cell lymphoma 1-derived peptide) to block the active site of GSK-3 $\beta$ showed promising results. These silica NPs enabled intracellular delivery and promoted NSPC self-renewal [175]. Moreover, curcumin, which as noted above 
acts as an $A \beta$ aggregation inhibitor, also promoted neurogenesis through direct regulation of the Wnt $/ \beta$-catenin pathway. NPs greatly improved the bioavailability of curcumin in the brain and offered a platform to achieve intracellular delivery and sustained/controlled release. Curcumin encapsulated in PLGA NPs stimulated NSPC proliferation and differentiation in the hippocampus and SVZ areas of rat brains as well as increasing nuclear translocation of $\beta$-catenin and decreasing GSK-3 $\beta$ levels. Finally, curcumin NPs have the capability to reverse $\mathrm{A} \beta$-impaired learning and memory in an $\mathrm{AD}$ rat model [176].

Under normal basal conditions, adult NSPCs produce neuroblasts before sequentially migrating and integrating into the olfactory bulb and hippocampus, respectively. When neural damage occurs, inflammatory mediators and chemokines, which recruit neurogenesis-produced newborn precursors to the damaged site, are primarily responsible for NSPC migration [177]. NPs decorated with these inflammatory mediators and chemokines can potentially manipulate migration and repair the injured regions. Leukemia inhibitory factor (a regulator of stem cell mobilization) and HGF (a pleiotropic cytokine of mesenchymal origin that enhances NSPC recruitment into the lesion) are good candidates for regulating NSPC migration. Li et al. [178] revealed that leukemia inhibitory factorloaded NPs combined with HGF-loaded hydrogels could manipulate the mobilization and migration of human NSPCs in vitro [178]. Moreover, nanostructured hydrogels functionalized with phage-derived peptides successfully induced NSPC differentiation and supported NSPC proliferation in vitro [179].

Differentiation is another crucial part of neurogenesis. Nanotechnology has great potential for promoting neural differentiation. For example, as discussed above, curcumin-encapsulated PLGA NPs can boost endogenous neurogenesis and stimulate newly born cells to differentiate into mature neurons in the SVZ and dentate gyrus [176]. Histamine, a neurotransmitter, is involved in a broad range of physiological functions including arousal, anxiety, learning and memory [180]. Bernardino et al. [181] found that PLGA-labeled histamine NPs stimulated neurogenesis in vitro and triggered SVZ cell differentiation into mature neurons both in vivo and in vitro [181]. As previous reports suggest, retinoic acid (RA) has nuclear receptors and is involved in axonal regeneration and neural differentiation in the brain and also maintains the differentiated state of adult neurons [182]. However, RA has low solubility in aqueous solution and is rapidly metabolized, which can be overcome by loading using nanotechnology. RA-loaded polymeric NPs released RA into cells at higher concentrations compared with free RA. RA-loaded polymeric NPs also modulated the differentiation of SVZ cells into neurons [183]. In a later study, Santos et al. [184] demonstrated that RA-loaded polymeric NPs might be a potent tool to induce differentiation of SVZ NSPCs. The nanoformulated RA boosted axonogenesis, avoided using solvents and could potentially be engineered to target NSPC differentiation [184]. Moreover, the strong ROS-scavenging ability of nanoceria also stimulated the proliferation and differentiation of PC12 cells [185].

Nanomaterials, in addition to delivering bioagents across the BBB and targeting specific areas of the brain, can also play therapeutic roles by exploiting pathological mechanisms. Impaired neurogenesis is a common characteristic of all NDs and stroke, and contributes to different types of neurological and psychiatric disorders [186]. Current research suggests that nanotechnology not only stimulates the generation, migration and neuronal differentiation of NSPCs but can also be applied to AD, PD, stroke treatment and other neurological disorders. Considering the great potential of nanotechnology, investigating how to use nanotechnology to mobilize endogenous NSPCs is just starting.

\section{Conclusion \& future perspective}

CNS diseases have huge impacts on the lives of affected patients. Currently available treatments for CNS diseases only temporarily alleviate symptoms. Nanotechnology serves as an exciting and promising new means to diagnose, treat and monitor CNS diseases.

By employing active biomaterials, gene therapy, cell therapy and signaling molecules - combined with multidisciplinary research areas including chemistry, biology, physics, mathematics and engineering - nanotechnology has become a leading contributor to CNS diseases research and may potentially hold the key to the future detection, treatment and follow-up of CNS diseases [187].

Currently, difficulties in early detection, the presence of the BBB, concerns about drug biocompatibility and poor targeting efficiency with traditional methods have limited CNS diseases treatment. For early diagnosis, nanotechnology offers methods with higher specificity and sensitivity to more accurately detect CNS diseasesassociated biomarkers. Also, due to their excellent biocompatibility, biodegradation, ability to multiload, and targeted and controlled drug delivery, nanodetection and nanomedicine have made great contributions to CNS diseases treatment [188]. 


\begin{tabular}{|c|c|c|c|c|c|}
\hline Nanomaterials & $\begin{array}{l}\text { Therapeutic } \\
\text { agent }\end{array}$ & Target ligand & Model & Outcomes & Ref. \\
\hline \multirow{2}{*}{$\begin{array}{l}\text { PLGA nanoparticles } \\
\text { and HAMC }\end{array}$} & \multirow[t]{5}{*}{ EGF and EPO } & \multirow[t]{5}{*}{ PEG } & \multirow[t]{2}{*}{ Stroke model mice } & - Attenuated the inflammatory response of brain tissue & \multirow[t]{2}{*}{ [168] } \\
\hline & & & & - Repaired and minimized damage in a mouse stroke model & \\
\hline \multirow{3}{*}{$\begin{array}{l}\mathrm{CeO}_{2} \text { or ceria } \\
\text { nanoparticles or } \\
\text { nanoceria }\end{array}$} & & & \multirow{3}{*}{$\begin{array}{l}\text { Hypobaric hypoxia } \\
\text { exposure rat model }\end{array}$} & - Significantly reduced oxidative stress damage & \multirow[t]{3}{*}{ [169] } \\
\hline & & & & - Ameliorated hypoxia-induced memory impairment & \\
\hline & & & & - Promoted neurogenesis & \\
\hline Silica nanoparticles & GFPeFRATtide & GFPeFRATtide & $\begin{array}{l}\text { Cultured human } \\
\text { embryonic kidney } \\
\text { epithelial cells and } \\
\text { NSCs }\end{array}$ & $\begin{array}{l}\text { - Increased the intracellular levels of c-MYC protein, which can } \\
\text { potentially impact stem cell proliferation and differentiation }\end{array}$ & [175] \\
\hline \multirow[t]{2}{*}{ PLGA nanoparticles } & \multirow[t]{2}{*}{ Curcumin } & \multirow[t]{2}{*}{-} & \multirow[t]{2}{*}{$\begin{array}{l}A \beta \text {-induced } \\
\text { neurotoxicity model } \\
\text { rats }\end{array}$} & $\begin{array}{l}\text { - Increased expression of genes involved in cell proliferation } \\
\text { (reelin, nestin and Pax6) and neuronal differentiation (neurogenin, } \\
\text { neuroD1, neuregulin, neuroligin and Stat3) }\end{array}$ & \multirow[t]{2}{*}{ [176] } \\
\hline & & & & - Reversed learning and memory impairments & \\
\hline $\begin{array}{l}\text { PLGA nanoparticles } \\
\text { and hydrogels }\end{array}$ & HGF and LIF & - & $\begin{array}{l}\text { Human neural stem } \\
\text { cells }\end{array}$ & - Significantly mobilized hNSCs and promoted their migration & [178] \\
\hline \multirow[t]{2}{*}{ PLGA nanoparticles } & \multirow[t]{2}{*}{ Histamine } & \multirow[t]{2}{*}{-} & SVZ cells & - Significantly increased the percentage of NeuN-positive neurons & \multirow[t]{2}{*}{ [181] } \\
\hline & & & GFP transgenic mice & $\begin{array}{l}\text { - Induced neuronal differentiation of grafted cells in the DGs of } \\
\text { hippocampal slices }\end{array}$ & \\
\hline \multirow{2}{*}{$\begin{array}{l}\text { Polymeric } \\
\text { nanoparticles }\end{array}$} & \multirow[t]{2}{*}{ Retinoic acid } & \multirow[t]{2}{*}{-} & SVZ cells & - Increased the number of $\mathrm{NeuN}$-positive neurons & [183] \\
\hline & & & C57BL/6 mice & $\begin{array}{l}\text { - Induced the expression of proneurogenic genes in the SVZ } \\
\text { neurogenic niche }\end{array}$ & [184] \\
\hline
\end{tabular}

Personalized treatment based on monitoring the efficacy and safety of treatment progress would greatly benefit clinical outcomes of complex CNS diseases. The term theranostics was coined to indicate concomitant therapeutic and diagnostic properties in a single agent. Combined with nanotechnology, diagnosis and therapy can exist within a single multifunctional nanomaterial, known as 'theranostic NPs' [189]. The ideal theranostic NP would selectively target the diseased tissue and have an effective therapeutic action. We believe that the development of effective theranostic NPs is critical for successful future CNS diseases therapy. Theranostic-based nanotechnology is expected to lead to major advances in precision and personalized medicine.

Multiple dysfunctions such as impaired neurogenesis, inflammatory imbalance, mitochondrial dysfunction and oxidative stress have been observed in several CNS diseases. Nanotechnology can be used to optimize drug formulations and combine multiple drugs into a single NP for synergistic therapeutic benefits. Moreover, being able to control time and dosage of drug release using NPs would also improve therapeutic efficiency. Furthermore, as these dysfunctions are commonly observed in different neurodegenerative diseases, nanotechnology-based therapeutic strategies that are being investigated in specific CNS diseases might easily be repositioned to other CNS diseases.

Application of nanotechnology in CNS diseases treatment still faces limitations and challenges. One critical issue for the development and translation of nanomedicines to clinical practice is safety concerns. In the brain, nanomaterials may induce inflammation, apoptosis and oxidative stress [190]. Thus, the biodegradation of nanocarriers from the brain is critical and should be taken into consideration in future design.

So far there is no specific method to determine the toxicity level and targeted drug release in the CNS. Furthermore, several studies reported that certain NPs grow naturally in our bodies, which could be a long-term health concern [191]. As such, a comprehensive testing program including pharmacokinetics, biodistribution, and acute and chronic toxicological testing is required before the introduction of NPs into clinical trials and practice. Also, considering the unique nature of each NP, it is necessary to understand the specific issues associated with each type of NP when evaluating toxicity. To address this, standardization and strict regulation of nanomaterials for clinical trials are required. Application of organic and degradable NPs, which could minimize toxicity concerns, would be of greatest benefit in this area. In addition, understanding the mechanism of nanomaterial-caused toxicity will help to benefit to minimize potential risk.

Another aspect limits the application of nanotechnology in CNS disease is the specific targeting. Although nanotechnology has greatly improved targeting specificity, formulations designed for brain delivery still accumulate 
in other regions of the body such as the liver and kidney. Thus, specific remote triggering of drug release is important for specific function and to reduce off-target effects. The design of triggerable nanoformulations will facilitate the clinical translation of nanomedicine in CNS diseases treatment. Furthermore, development of NPs that could target specific brain cells such as dopaminergic neurons for PD and microglia for neuroinflammation would also enhance their potential therapeutic value. Furthermore, the administration route used to delivery NPs also effects

Executive summary

Nanotechnology has considerable potential \& advantages for CNS diseases diagnosis \& treatment

- Modified nanomaterials can be used to target damaged cells and tissues in CNS diseases via molecular-scale interactions.

- Nanoengineered materials can simultaneously sustain drug release, enhance bioavailability, deliver multiple agents and protect compounds from degradation when surface modified with distinct molecules. These nanomaterial properties place them at the forefront of future diagnostic and therapeutic opportunities for neurodegenerative diseases (NDs).

Nanotechnology represents a promising approach for Alzheimer's disease diagnosis \& treatment, both in solution

$\&$ in living animals

- Nanotechnology has been applied to target amyloid- $\beta(A \beta)$ peptide and its aggregated forms. Exciting progress has been made in this area, with positive outcomes in modulating $A \beta$ production, inhibiting $A \beta$ aggregation, enhancing $A \beta$ clearance and even reversing $A \beta$-induced-learning and memory deficits in Alzheimer's disease (AD) model mice. Overall, targeting $A \beta$ with nanotechnology is a promising approach to manage, delay and even treat AD.

- Also, targeting other AD pathogenesis, such as inflammation and oxidative stress nanotechnology, is a promising approach to manage, delay and even treat AD.

- Applying nanotechnology to detect AD biomarkers in a molecular range holds great promise for translation to clinical use and improving patient outcomes.

Application of nanotechnology in both dopamine replacement \& neuroprotection presents a wide range of possibilities for Parkinson's disease

- Nanotechnology-based treatment strategy including dopamine replacement, targeting $\alpha$-synuclein accumulation, targeting inflammation, targeting antioxidative stress and neurotrophic factor supplementation have been applied for Parkinson's disease (PD) treatment.

- A number of nanotechnology-based approaches have been developed to detect $\alpha$-synuclein, dopamine and mitochondrial dysfunction.

Nanotechnology presents numerous advantages \& opportunities in stroke

- Application of nanotechnology in stroke including enhanced blood-brain barrier permeability and the capacity for sustained and controlled drug release.

- Most research on nanotechnology-based therapeutics in stroke have focused on applying these advantages to preventing oxidative stress, inflammation and apoptosis.

Enhancing neuroregeneration may have promising therapeutic potential for CNS diseases

- Nanotechnology has been studied to maximize blood-brain barrier permeability for drug delivery, achieve sustained drug release and deliver multiple targets for restoring endogenous neurogenesis.

- Nanotechnology not only stimulates the generation, migration and neuronal differentiation of neural stem/precursor cells but can also be applied to ND treatment and other neurological disorders.

Conclusion \& future perspective

- For early diagnosis, nanotechnology offers methods with higher specificity and sensitivity to more accurately detect ND-associated biomarkers. Also, due to their excellent biocompatibility, biodegradation, ability to multiload, and targeted and controlled drug delivery, nanodetection and nanomedicine have made great contributions to ND treatment.

- Theranostic-based nanotechnology is expected to lead to major advances in precision and personalized medicine.

- Several common dysfunctions, such as impaired neurogenesis, inflammatory imbalance, mitochondrial dysfunction and oxidative stress, have been observed in several NDs. Thus, nanotechnology-based therapeutic strategies that are being investigated in one specific disease might easily be repositioned to other NDs.

- The design of triggerable nanoformulations will facilitate the clinical translation of nanomedicine in ND treatment. Furthermore, development of nanoparticles (NPs) that could target specific brain cells such as dopaminergic neurons for PD and microglia for neuroinflammation would also enhance their potential therapeutic value.

- It is necessary to understand the specific issues associated with each type of NP when evaluating toxicity. To address this, standardization and strict regulation of nanomaterials for clinical trials are required. Application of organic and degradable NPs, which could minimize toxicity concerns, would be of greatest benefit in this area. 
its efficiency to reach the brain. For instance, intravenously injected NPs would be exposed to blood plasma, where they would bind competitively with proteins and many other complex biomolecules. Also, some studies showed that inhaled NPs could cause harmful inflammation and brain damage. Thus, a safe and high efficiency administration route for each specific NP must be developed.

Apart from the health risk and targeting specific concerns, NPs are also very expensive. The complex design and engineering process makes nanomedicine unaffordable for patients. To favor translation of research work to clinic application, future studies need to consider cost-effective formulation design.

Despite these concerns, nanotechnology holds a number of advantages compared with traditional CNS diseases treatments. There remain unsolved problems, but nanomedicine is still relatively new and has great potential for translation to clinical use as smarter and better tools for the diagnosis, treatment and monitoring of CNS diseases.

\section{Financial \& competing interests disclosure}

This work was supported by the Joint Program of Yunnan Province and Kunming Medical University (2017FE468-249, ZY He), and the Fund of Yunnan Key Laboratory of Stem Cell and Regenerative Medicine (ZY He). The authors have no relevant affiliations or financial involvement with any organization or entity with a financial interest in or financial conflict with the subject matter or materials discussed in the manuscript. This includes employment, consultancies, honoraria, stock ownership or options, expert testimony, grants or patents received or pending or royalties.

No writing assistance was utilized in the production of this manuscript.

Open access

This work is licensed under the Attribution-NonCommercial-NoDerivatives 4.0 Unported License. To view a copy of this license, visit http://creativecommons.org/licenses/by-nc-nd/4.0/

\section{References}

Papers of special note have been highlighted as: • of interest; $\bullet \bullet$ of considerable interest

1. Querfurth HW, Laferla FM. Alzheimer's disease. N. Engl. J. Med. 362(4), 329-344 (2010).

2. Archibald N, Burn D. Parkinson's disease. Medicine 36(12), 630-635 (2008).

3. Mozaffarian D, Benjamin EJ, Go AS et al. Heart disease and stroke statistics-2015 update: a report from the American Heart Association. Circulation 131(4), e29-e322 (2015).

4. Ballabh P, Braun A, Nedergaard M. The blood-brain barrier: an overview: structure, regulation, and clinical implications. Neurobiol. Dis. 16(1), 1-13 (2004).

5. Abbott NJ, Patabendige AA, Dolman DE, Yusof SR, Begley DJ. Structure and function of the blood-brain barrier. Neurobiol. Dis. 37(1), $13-25$ (2010).

6. Silva GA. Neuroscience nanotechnology: progress, opportunities and challenges. Nat. Rev. Neurosci. 7(1), 65-74 (2006).

7. Moghimi SM, Hunter AC, Murray JC. Nanomedicine: current status and future prospects. FASEB J. 19(3), 311-330 (2005).

8. Serrano-Pozo A, Frosch MP, Masliah E, Hyman BT. Neuropathological alterations in Alzheimer disease. Cold Spring Harb. Perspect. Med. 1(1), a006189 (2011).

9. Hardy J, Selkoe DJ. The amyloid hypothesis of Alzheimer's disease: progress and problems on the road to therapeutics. Science 297(5580), 353-356 (2002).

10. Gilbert BJ. The role of amyloid beta in the pathogenesis of Alzheimer's disease. J. Clin. Pathol. 66(5), $362-366$ (2013).

11. Haass C, Kaether C, Thinakaran G, Sisodia S. Trafficking and proteolytic processing of APP. Cold Spring Harb. Perspect. Med. 2(5), a006270 (2012).

12. Li S, Liu Z, Ji F et al. Delivery of quantum dot-siRNA nanoplexes in SK-N-SH cells for BACE1 gene silencing and intracellular imaging. Mol. Ther. Nucleic Acids 1, e20 (2012).

13. Alvarez-Erviti L, Seow Y, Yin H, Betts C, Lakhal S, Wood MJ. Delivery of siRNA to the mouse brain by systemic injection of targeted exosomes. Nat. Biotechnol. 29(4), 341-345 (2011).

•• Excellent research on using targeted exosomes to decrease amyloid- $\beta$ production.

14. Fernandez JW, Rezai-Zadeh K, Obregon D, Tan J. EGCG functions through estrogen receptor-mediated activation of ADAM10 in the promotion of non-amyloidogenic processing of APP. FEBS Lett. 584(19), 4259-4267 (2010).

15. Smith A, Giunta B, Bickford PC, Fountain M, Tan J, Shytle RD. Nanolipidic particles improve the bioavailability and alpha-secretase inducing ability of epigallocatechin-3-gallate (EGCG) for the treatment of Alzheimer's disease. Int. J. Pharm. 389(1-2), 207-212 (2010).

16. Mangialasche F, Solomon A, Winblad B, Mecocci P, Kivipelto M. Alzheimer's disease: clinical trials and drug development. Lancet Neurol. 9(7), 702-716 (2010). 
17. De Strooper B, Vassar R, Golde T. The secretases: enzymes with therapeutic potential in Alzheimer disease. Nat. Rev. Neurol. 6(2), 99-107 (2010).

18. Wang Q, Yu X, Li L, Zheng J. Inhibition of amyloid-beta aggregation in Alzheimer's disease. Curr. Pharm. Des. 20(8), 1223-1243 (2014).

19. Smith DG, Cappai R, Barnham KJ. The redox chemistry of the Alzheimer's disease amyloid beta peptide. Biochim. Biophys. Acta 1768(8), 1976-1990 (2007).

20. Bush AI, Tanzi RE. Therapeutics for Alzheimer's disease based on the metal hypothesis. Neurotherapeutics 5(3), 421-432 (2008).

21. Liu G, Men P, Kudo W, Perry G, Smith MA. Nanoparticle-chelator conjugates as inhibitors of amyloid-beta aggregation and neurotoxicity: a novel therapeutic approach for Alzheimer disease. Neurosci. Lett. 455(3), 187-190 (2009).

22. Mufamadi MS, Choonara YE, Kumar $\mathrm{P}$ et al. Surface-engineered nanoliposomes by chelating ligands for modulating the neurotoxicity associated with beta-amyloid aggregates of Alzheimer's disease. Pharm. Res. 29(11), 3075-3089 (2012).

23. Li M, Xu C, Wu L, Ren J, Wang E, Qu X. Self-assembled peptide-polyoxometalate hybrid nanospheres: two in one enhances targeted inhibition of amyloid beta-peptide aggregation associated with Alzheimer's disease. Small 9(20), 3455-3461 (2013).

24. Li M, Guan Y, Zhao A, Ren J, Qu X. Using multifunctional peptide conjugated Au nanorods for monitoring beta-amyloid aggregation and chemo-photothermal treatment of Alzheimer's disease. Theranostics 7(12), 2996-3006 (2017).

- Significant article on preventing and monitoring amyloid- $\beta$ aggregation by gold nanorods.

25. Airoldi C, Mourtas S, Cardona F et al. Nanoliposomes presenting on surface a cis-glycofused benzopyran compound display binding affinity and aggregation inhibition ability towards amyloid beta1-42 peptide. Eur. J. Med. Chem. 85, 43-50 (2014).

26. Darvesh AS, Carroll RT, Bishayee A, Novotny NA, Geldenhuys WJ, Van Der Schyf CJ. Curcumin and neurodegenerative diseases: a perspective. Expert Opin. Investig. Drugs 21(8), 1123-1140 (2012).

27. Cheng KK, Yeung CF, Ho SW, Chow SF, Chow AH, Baum L. Highly stabilized curcumin nanoparticles tested in an in vitro blood-brain barrier model and in Alzheimer's disease Tg2576 mice. AAPS J. 15(2), 324-336 (2013).

28. Taylor M, Moore S, Mourtas S et al. Effect of curcumin-associated and lipid ligand-functionalized nanoliposomes on aggregation of the Alzheimer's Abeta peptide. Nanomedicine 7(5), 541-550 (2011).

29. Soares TB, Loureiro L, Carvalho A et al. Lipid nanocarriers loaded with natural compounds: potential new therapies for age related neurodegenerative diseases? Prog. Neurobiol. doi: 10.1016/j.pneurobio.2018.04.004 (2018) (Epub ahead of print).

-. Excellent review on different natural compounds loaded into lipid nanocarriers to treat neurodegenerative diseases.

30. Baysal I, Yabanoglu-Ciftci S, Tunc-Sarisozen Y, Ulubayram K, Ucar G. Interaction of selegiline-loaded PLGA-b-PEG nanoparticles with beta-amyloid fibrils. J. Neural Transm. 120(6), 903-910 (2013).

31. Li M, Zhao A, Dong K, Li W, Ren J, Qu X. Chemically exfoliated WS2 nanosheets efficiently inhibit amyloid $\beta$-peptide aggregation and can be used for photothermal treatment of Alzheimer's disease. Nano Res. 8(10), 3216-3227 (2015).

32. Bana L, Minniti S, Salvati E et al. Liposomes bi-functionalized with phosphatidic acid and an ApoE-derived peptide affect Abeta aggregation features and cross the blood-brain-barrier: implications for therapy of Alzheimer disease. Nanomedicine 10(7), 1583-1590 (2014).

33. Balducci C, Mancini S, Minniti S et al. Multifunctional liposomes reduce brain beta-amyloid burden and ameliorate memory impairment in Alzheimer's disease mouse models. J. Neurosci. 34(42), 14022-14031 (2014).

34. Dykman LA, Khlebtsov NG. Gold nanoparticles in biology and medicine: recent advances and prospects. Acta Naturae 3(2), 34-55 (2011).

35. Kogan MJ, Bastus NG, Amigo R et al. Nanoparticle-mediated local and remote manipulation of protein aggregation. Nano Lett. 6(1), $110-115$ (2006).

36. Araya E, Olmedo I, Bastus NG et al. Gold nanoparticles and microwave irradiation inhibit beta-amyloid amyloidogenesis. Nanoscale Res. Lett. 3(11), 435-443 (2008).

37. Prades R, Guerrero S, Araya E et al. Delivery of gold nanoparticles to the brain by conjugation with a peptide that recognizes the transferrin receptor. Biomaterials 33(29), 7194-7205 (2012).

38. Morales-Zavala F, Arriagada H, Hassan N et al. Peptide multifunctionalized gold nanorods decrease toxicity of beta-amyloid peptide in a Caenorhabditis elegans model of Alzheimer's disease. Nanomedicine 13(7), 2341-2350 (2017).

39. Tanzi RE, Moir RD, Wagner SL. Clearance of Alzheimer's Abeta peptide: the many roads to perdition. Neuron 43(5), 605-608 (2004).

40. Mawuenyega KG, Sigurdson W, Ovod V et al. Decreased clearance of CNS beta-amyloid in Alzheimer's disease. Science 330(6012), 1774 (2010).

41. Liu YH, Giunta B, Zhou HD, Tan J, Wang YJ. Immunotherapy for Alzheimer disease: the challenge of adverse effects. Nat. Rev. Neurol. $8(8), 465-469$ (2012).

42. Kuai R, Li D, Chen YE, Moon JJ, Schwendeman A. High-density lipoproteins: nature's multifunctional nanoparticles. ACS Nano 10(3), 3015-3041 (2016). 
43. Song Q, Huang M, Yao L et al. Lipoprotein-based nanoparticles rescue the memory loss of mice with Alzheimer's disease by accelerating the clearance of amyloid-beta. ACS Nano 8(3), 2345-2359 (2014).

44. Demattos RB, Bales KR, Cummins DJ, Paul SM, Holtzman DM. Brain to plasma amyloid-beta efflux: a measure of brain amyloid burden in a mouse model of Alzheimer's disease. Science 295(5563), 2264-2267 (2002).

45. Mancini S, Balducci C, Micotti E et al. Multifunctional liposomes delay phenotype progression and prevent memory impairment in a presymptomatic stage mouse model of Alzheimer disease. J. Control. Rel. 258, 121-129 (2017).

46. Mancini S, Minniti S, Gregori M et al. The hunt for brain Abeta oligomers by peripherally circulating multi-functional nanoparticles: potential therapeutic approach for Alzheimer disease. Nanomedicine 12(1), 43-52 (2016).

47. Songjiang Z, Lixiang W. Amyloid-beta associated with chitosan nano-carrier has favorable immunogenicity and permeates the BBB. AAPS PharmSciTech. 10(3), 900-905 (2009).

48. Puras G, Salvador A, Igartua M, Hernandez RM, Pedraz JL. Encapsulation of Abeta(1-15) in PLGA microparticles enhances serum antibody response in mice immunized by subcutaneous and intranasal routes. Eur. J. Pharm. Sci. 44(3), 200-206 (2011).

49. Canovi M, Markoutsa E, Lazar AN et al. The binding affinity of anti-Abeta1-42 MAb-decorated nanoliposomes to Abeta1-42 peptides in vitro and to amyloid deposits in post-mortem tissue. Biomaterials 32(23), 5489-5497 (2011).

50. Ordonez-Gutierrez L, Posado-Fernandez A, Ahmadvand D et al. ImmunoPEGliposome-mediated reduction of blood and brain amyloid levels in a mouse model of Alzheimer's disease is restricted to aged animals. Biomaterials 112, 141-152 (2017).

51. Haass C, Selkoe DJ. Soluble protein oligomers in neurodegeneration: lessons from the Alzheimer's amyloid beta-peptide. Nat. Rev. Mol. Cell Biol. 8(2), 101-112 (2007).

52. Selkoe DJ, Hardy J. The amyloid hypothesis of Alzheimer's disease at 25 years. EMBO Mol. Med. 8(6), 595-608 (2016).

53. Heckman KL, Decoteau W, Estevez A et al. Custom cerium oxide nanoparticles protect against a free radical mediated autoimmune degenerative disease in the brain. ACS Nano 7(12), 10582-10596 (2013).

54. Dowding JM, Song W, Bossy K et al. Cerium oxide nanoparticles protect against Abeta-induced mitochondrial fragmentation and neuronal cell death. Cell Death Differ. 21(10), 1622-1632 (2014).

55. Naz S, Beach J, Heckert B et al. Cerium oxide nanoparticles: a 'radical' approach to neurodegenerative disease treatment. Nanomedicine (Lond.) 12(5), 545-553 (2017).

-. Excellent review of cerium oxide nanoparticles (NPs) application in neurodegenerative disease treatment.

56. Cimini A, D'angelo B, Das $S$ et al. Antibody-conjugated PEGylated cerium oxide nanoparticles for specific targeting of A $\beta$ aggregates modulate neuronal survival pathways. Acta Biomater. 8(6), 2056-2067 (2012).

57. Miller AM, Piazza A, Martin DS et al. The deficit in long-term potentiation induced by chronic administration of amyloid-beta is attenuated by treatment of rats with a novel phospholipid-based drug formulation, VP025. Exp. Gerontol. 44(4), 300-304 (2009).

58. Kim MJ, Rehman SU, Amin FU, Kim MO. Enhanced neuroprotection of anthocyanin-loaded PEG-gold nanoparticles against Abeta1-42-induced neuroinflammation and neurodegeneration via the NF-KB/JNK/GSK3beta signaling pathway. Nanomedicine 13(8), 2533-2544 (2017).

59. Sanchez-Lopez E, Ettcheto M, Egea MA et al. New potential strategies for Alzheimer's disease prevention: pegylated biodegradable dexibuprofen nanospheres administration to APPswe/PS1dE9. Nanomedicine 13(3), 1171-1182 (2017).

60. Hort J, O'brien JT, Gainotti G et al. EFNS guidelines for the diagnosis and management of Alzheimer's disease. Eur. J. Neurol. 17(10), 1236-1248 (2010).

61. Morris JC. Early-stage and preclinical Alzheimer disease. Alzheimer Dis. Assoc. Disord. 19(3), 163-165 (2005).

62. Georganopoulou DG, Chang L, Nam JM et al. Nanoparticle-based detection in cerebral spinal fluid of a soluble pathogenic biomarker for Alzheimer's disease. Proc. Natl Acad. Sci. USA 102(7), 2273-2276 (2005).

63. Roney CA, Arora V, Kulkarni PV, Antich PP, Bonte FJ. Nanoparticulate radiolabelled quinolines detect amyloid plaques in mouse models of Alzheimer's disease. Int. J. Alzheimers Dis. 2009, 481031 (2009).

64. Yang J, Wadghiri YZ, Hoang DM et al. Detection of amyloid plaques targeted by USPIO-Abeta1-42 in Alzheimer's disease transgenic mice using magnetic resonance microimaging. NeuroImage 55(4), 1600-1609 (2011).

65. Gobbi M, Re F, Canovi M et al. Lipid-based nanoparticles with high binding affinity for amyloid-beta1-42 peptide. Biomaterials 31(25), 6519-6529 (2010).

66. Mourtas S, Canovi M, Zona C et al. Curcumin-decorated nanoliposomes with very high affinity for amyloid-beta1-42 peptide. Biomaterials 32(6), 1635-1645 (2011).

67. Le Droumaguet B, Nicolas J, Brambilla D et al. Versatile and efficient targeting using a single nanoparticulate platform: application to cancer and Alzheimer's disease. ACS Nano 6(7), 5866-5879 (2012).

68. Brambilla D, Verpillot R, Le Droumaguet B et al. PEGylated nanoparticles bind to and alter amyloid-beta peptide conformation: toward engineering of functional nanomedicines for Alzheimer's disease. ACS Nano 6(7), 5897-5908 (2012).

69. Salvati E, Re F, Sesana S et al. Liposomes functionalized to overcome the blood-brain barrier and to target amyloid-beta peptide: the chemical design affects the permeability across an in vitro model. Int. J. Nanomedicine 8, 1749-1758 (2013). 
70. Zhang C, Wan X, Zheng X et al. Dual-functional nanoparticles targeting amyloid plaques in the brains of Alzheimer's disease mice. Biomaterials 35(1), 456-465 (2014).

71. Tanifum EA, Dasgupta I, Srivastava M et al. Intravenous delivery of targeted liposomes to amyloid-beta pathology in APP/PSEN1 transgenic mice. PLoS ONE 7(10), e48515 (2012).

72. Sperling RA, Aisen PS, Beckett LA et al. Toward defining the preclinical stages of Alzheimer's disease: recommendations from the National Institute on Aging-Alzheimer's Association workgroups on diagnostic guidelines for Alzheimer's disease. Alzheimers Dement. 7(3), 280-292 (2011).

73. Neely A, Perry C, Varisli B et al. Ultrasensitive and highly selective detection of Alzheimer's disease biomarker using two-photon Rayleigh scattering properties of gold nanoparticle. ACS Nano 3(9), 2834-2840 (2009).

74. Stegurova L, Draberova E, Bartos A, Draber P, Ripova D, Draber P. Gold nanoparticle-based immuno-PCR for detection of tau protein in cerebrospinal fluid. J. Immunol. Methods 406, 137-142 (2014).

75. Zengin A, Tamer U, Caykara T. A SERS-based sandwich assay for ultrasensitive and selective detection of Alzheimer's tau protein. Biomacromolecules 14(9), 3001-3009 (2013).

76. Kaushik A, Jayant RD, Tiwari S, Vashist A, Nair M. Nano-biosensors to detect beta-amyloid for Alzheimer's disease management. Biosens. Bioelectron. 80, 273-287 (2016).

77. Yarnall A, Archibald N, Burn D. Parkinson's disease. Medicine 40(10), 529-535 (2012).

78. Lees AJ, Hardy J, Revesz T. Parkinson's disease. Lancet 373(9680), 2055-2066 (2009).

79. Connolly BS, Lang AE. Pharmacological treatment of Parkinson disease: a review. JAMA 311(16), 1670-1683 (2014).

80. Olanow CW. The scientific basis for the current treatment of Parkinson's disease. Annu. Rev. Med. 55, 41-60 (2004).

81. Dexter DT, Jenner P. Parkinson disease: from pathology to molecular disease mechanisms. Free Radic. Biol. Med. 62, 132-144 (2013).

82. Carlsson T, Bjorklund T, Kirik D. Restoration of the striatal dopamine synthesis for Parkinson's disease: viral vector-mediated enzyme replacement strategy. Curr. Gene Ther. 7(2), 109-120 (2007).

83. Bargiotas P, Konitsiotis S. Levodopa-induced dyskinesias in Parkinson's disease: emerging treatments. Neuropsychiatr. Dis. Treat 9 , 1605-1617 (2013).

84. Kura AU, Hussein Al Ali SH, Hussein MZ, Fakurazi S, Arulselvan P. Development of a controlled-release anti-parkinsonian nanodelivery system using levodopa as the active agent. Int. J. Nanomedicine 8, 1103-1110 (2013).

85. Gambaryan PY, Kondrasheva IG, Severin ES, Guseva AA, Kamensky AA. Increasing the efficiency of Parkinson's disease treatment using a poly(lactic-co-glycolic acid) (PLGA) based L-DOPA delivery system. Exp. Neurobiol. 23(3), 246-252 (2014).

86. Pahuja R, Seth K, Shukla A et al. Trans-blood brain barrier delivery of dopamine-loaded nanoparticles reverses functional deficits in parkinsonian rats. ACS Nano 9(5), 4850-4871 (2015).

87. Lashuel HA, Overk CR, Oueslati A, Masliah E. The many faces of alpha-synuclein: from structure and toxicity to therapeutic target. Nat. Rev. Neurosci. 14(1), 38-48 (2013).

88. Olanow CW, Brundin P. Parkinson's disease and alpha synuclein: is Parkinson's disease a prion-like disorder? Mov. Disord. 28(1), 31-40 (2013).

89. Lee VM, Trojanowski JQ. Mechanisms of Parkinson's disease linked to pathological alpha-synuclein: new targets for drug discovery. Neuron 52(1), 33-38 (2006).

90. Loureiro JA, Gomes B, Coelho MA, Do Carmo Pereira M, Rocha S. Immunoliposomes doubly targeted to transferrin receptor and to alpha-synuclein. Future Sci. OA 1(4), FSO71 (2015).

91. Taebnia N, Morshedi D, Yaghmaei S, Aliakbari F, Rahimi F, Arpanaei A. Curcumin-loaded amine-functionalized mesoporous silica nanoparticles inhibit alpha-synuclein fibrillation and reduce its cytotoxicity-associated effects. Langmuir 32(50), 13394-13402 (2016).

92. Niu S, Zhang LK, Zhang L et al. Inhibition by multifunctional magnetic nanoparticles loaded with alpha-synuclein RNAi plasmid in a Parkinson's disease model. Theranostics 7(2), 344-356 (2017).

•• Excellent article displaying multifunctional nanoparticles (NPs) for inhibiting $\alpha$-synuclein production.

93. Mcgeer PL, Mcgeer EG. Inflammation and neurodegeneration in Parkinson's disease. Parkinsonism Relat. Disord. 10(Suppl. 1) S3-S7 (2004).

94. Crotty S, Fitzgerald P, Tuohy E et al. Neuroprotective effects of novel phosphatidylglycerol-based phospholipids in the 6-hydroxydopamine model of Parkinson's disease. Eur. J. Neurosci. 27(2), 294-300 (2008).

95. Fitzgerald P, Mandel A, Bolton AE, Sullivan AM, Nolan Y. Treatment with phosphotidylglycerol-based nanoparticles prevents motor deficits induced by proteasome inhibition: implications for Parkinson's disease. Behav. Brain Res. 195(2), 271-274 (2008).

96. Liu Y, Guo Y, An S et al. Targeting caspase-3 as dual therapeutic benefits by RNAi facilitating brain-targeted nanoparticles in a rat model of Parkinson's disease. PLoS ONE 8(5), e62905 (2013).

97. Subramaniam SR, Chesselet MF. Mitochondrial dysfunction and oxidative stress in Parkinson's disease. Prog. Neurobiol. 106-107, 17-32 (2013). 
98. Cai X, Jia H, Liu Z et al. Polyhydroxylated fullerene derivative $\mathrm{C}(60)(\mathrm{OH})(24)$ prevents mitochondrial dysfunction and oxidative damage in an $\mathrm{MPP}(+)$-induced cellular model of Parkinson's disease. J. Neurosci. Res. 86(16), 3622-3634 (2008).

99. Dillon C, Billings M, Hockey K, Delagarza L, Rzigalinski B. Cerium oxide nanoparticles protect against MPTP-induced dopaminergic neurodegeneration in a mouse model for Parkinson's disease. Presented at: NSTI-Nanotech. Boston, MA, USA. (June 13-16 2011).

100. Bollimpelli VS, Kumar P, Kumari S, Kondapi AK. Neuroprotective effect of curcumin-loaded lactoferrin nano particles against rotenone induced neurotoxicity. Neurochem. Int. 95, 37-45 (2016).

101. Siddique YH, Khan W, Singh BR, Naqvi AH. Synthesis of alginate-curcumin nanocomposite and its protective role in transgenic Drosophila model of Parkinson's disease. ISRN Pharmacol. 2013, 794582 (2013).

102. Reddy MK, Wu L, Kou W, Ghorpade A, Labhasetwar V. Superoxide dismutase-loaded PLGA nanoparticles protect cultured human neurons under oxidative stress. Appl. Biochem. Biotechnol. 151(2-3), 565-577 (2008).

103. Pangeni R, Sharma S, Mustafa G, Ali J, Baboota S. Vitamin E loaded resveratrol nanoemulsion for brain targeting for the treatment of Parkinson's disease by reducing oxidative stress. Nanotechnology 25(48), 485102 (2014).

104. Battigelli A, Russier J, Venturelli E et al. Peptide-based carbon nanotubes for mitochondrial targeting. Nanoscale 5(19), 9110-9117 (2013).

105. Boddapati SV, D'souza GG, Erdogan S, Torchilin VP, Weissig V. Organelle-targeted nanocarriers: specific delivery of liposomal ceramide to mitochondria enhances its cytotoxicity in vitro and in vivo. Nano Lett. 8(8), 2559-2563 (2008).

106. Wang X, Shao N, Zhang Q, Cheng Y. Mitochondrial targeting dendrimer allows efficient and safe gene delivery. J. Mater. Chem. B 2(17), 2546-2553 (2014).

107. Brenza TM, Ghaisas S, Ramirez JEV et al. Neuronal protection against oxidative insult by polyanhydride nanoparticle-based mitochondria-targeted antioxidant therapy. Nanomedicine 13(3), 809-820 (2017).

- Significant article on mitochondria-targeting NPs combats oxidative stress.

108. Kurakhmaeva KB, Djindjikhashvili IA, Petrov VE et al. Brain targeting of nerve growth factor using poly(butyl cyanoacrylate) nanoparticles. J. Drug Target. 17(8), 564-574 (2009).

109. Huang R, Ke W, Liu Y et al. Gene therapy using lactoferrin-modified nanoparticles in a rotenone-induced chronic Parkinson model. J. Neurol. Sci. 290(1-2), 123-130 (2010).

110. Huang R, Han L, Li J et al. Neuroprotection in a 6-hydroxydopamine-lesioned Parkinson model using lactoferrin-modified nanoparticles. J. Gene Med. 11(9), 754-763 (2009).

111. Kansara S, Trivedi A, Chen S, Jankovic J, Le W. Early diagnosis and therapy of Parkinson's disease: can disease progression be curbed? J. Neural Transm. (Vienna) 120(1), 197-210 (2013).

112. An Y, Jiang X, Bi W et al. Sensitive electrochemical immunosensor for alpha-synuclein based on dual signal amplification using PAMAM dendrimer-encapsulated Au and enhanced gold nanoparticle labels. Biosens. Bioelectron. 32(1), 224-230 (2012).

113. An Y, Tang L, Jiang X et al. A photoelectrochemical immunosensor based on Au-doped TiO2 nanotube arrays for the detection of alpha-synuclein. Chemistry 16(48), 14439-14446 (2010).

114. Yue HY, Huang $\mathrm{S}$, Chang $\mathrm{J}$ et al. $\mathrm{ZnO}$ nanowire arrays on 3D hierachical graphene foam: biomarker detection of Parkinson's disease. ACS Nano 8(2), 1639-1646 (2014).

115. Ma W, Qin LX, Liu FT et al. Ubiquinone-quantum dot bioconjugates for in vitro and intracellular complex I sensing. Sci. Rep. 3, 1537 (2013).

116. Roger VL, Go AS, Lloyd-Jones DM et al. Heart disease and stroke statistics - 2012 update: a report from the American Heart Association. Circulation 125(1), e2-e220 (2012).

117. Moskowitz MA, Lo EH, Iadecola C. The science of stroke: mechanisms in search of treatments. Neuron 67(2), 181-198 (2010).

118. Donnan GA, Fisher M, Macleod M, Davis SM. Stroke. Lancet 371(9624), 1612-1623 (2008).

119. Caplan LR. Stroke thrombolysis: slow progress. Circulation 114(3), 187-190 (2006).

120. Prabhakaran S, Ruff I, Bernstein RA. Acute stroke intervention: a systematic review. JAMA 313(14), 1451-1462 (2015).

121. Chen JP, Yang PC, Ma YH, Lu YJ. Superparamagnetic iron oxide nanoparticles for delivery of tissue plasminogen activator. J. Nanosci. Nanotechnol. 11(12), 11089-11094 (2011).

122. Chen JP, Yang PC, Ma YH, Tu SJ, Lu YJ. Targeted delivery of tissue plasminogen activator by binding to silica-coated magnetic nanoparticle. Int. J. Nanomedicine 7, 5137-5149 (2012).

123. Yang HW, Hua MY, Lin KJ et al. Bioconjugation of recombinant tissue plasminogen activator to magnetic nanocarriers for targeted thrombolysis. Int. J. Nanomedicine 7, 5159-5173 (2012).

124. Tadayon A, Jamshidi R, Esmaeili A. Delivery of tissue plasminogen activator and streptokinase magnetic nanoparticles to target vascular diseases. Int. J. Pharm. 495(1), 428-438 (2015).

125. Cheng R, Huang W, Huang L et al. Acceleration of tissue plasminogen activator-mediated thrombolysis by magnetically powered nanomotors. ACS Nano 8(8), 7746-7754 (2014). 
126. Marsh JN, Hu G, Scott MJ et al. A fibrin-specific thrombolytic nanomedicine approach to acute ischemic stroke. Nanomedicine (Lond.) 6(4), 605-615 (2011).

127. Marsh JN, Senpan A, Hu G et al. Fibrin-targeted perfluorocarbon nanoparticles for targeted thrombolysis. Nanomedicine (Lond.) 2(4), 533-543 (2007).

128. Mccarthy JR, Sazonova IY, Erdem SS et al. Multifunctional nanoagent for thrombus-targeted fibrinolytic therapy. Nanomedicine (Lond.) 7(7), 1017-1028 (2012).

129. Kaur J, Zhao Z, Klein GM, Lo EH, Buchan AM. The neurotoxicity of tissue plasminogen activator? J. Cereb. Blood Flow Metab. 24(9), 945-963 (2004).

130. Kawaguchi AT, Haida M, Yamano M, Fukumoto D, Ogata Y, Tsukada H. Liposome-encapsulated hemoglobin ameliorates ischemicstroke in nonhuman primates: an acute study. J. Pharm. Exp. Ther.332(2), 429-436 (2010).

131. Kawaguchi AT, Haida M, Ohba H, Yamano M, Fukumoto D, Tsukada H. Liposome-encapsulated hemoglobin ameliorates ischemic stroke in nonhuman primates: longitudinal observation. Artif. Organs 37(10), 904-912 (2013).

132. Kaneda S, Ishizuka T, Sekiguchi A, Morimoto K, Kasukawa H. Efficacy of liposome-encapsulated hemoglobin in a rat model of cerebral ischemia. Artif. Organs 38(8), 650-655 (2014).

133. Molina CA, Alvarez-Sabin J. Recanalization and reperfusion therapies for acute ischemic stroke. Cerebrovasc. Dis. 27(Suppl. 1) 162-167 (2009).

134. Shimbo D, Abumiya T, Shichinohe H, Nakayama N, Kazumata K, Houkin K. Post-ischemic intra-arterial infusion of liposome-encapsulated hemoglobin can reduce ischemia reperfusion injury. Brain Res. 1554, 59-66 (2014).

135. Nakka VP, Gusain A, Mehta SL, Raghubir R. Molecular mechanisms of apoptosis in cerebral ischemia: multiple neuroprotective opportunities. Mol. Neurobiol. 37(1), 7-38 (2008).

136. Lee JC, Kim J, Park JK, Chung GH, Jang YS. The antioxidant, rather than prooxidant, activities of quercetin on normal cells: quercetin protects mouse thymocytes from glucose oxidase-mediated apoptosis. Exp. Cell Res. 291(2), 386-397 (2003).

137. Rivera F, Costa G, Abin A et al. Reduction of ischemic brain damage and increase of glutathione by a liposomal preparation of quercetin in permanent focal ischemia in rats. Neurotox. Res. 13(2), 105-114 (2008).

138. Ghosh A, Sarkar S, Mandal AK, Das N. Neuroprotective role of nanoencapsulated quercetin in combating ischemia-reperfusion induced neuronal damage in young and aged rats. PLoS ONE 8(4), e57735 (2013).

139. Das S, Mandal AK, Ghosh A, Panda S, Das N, Sarkar S. Nanoparticulated quercetin in combating age related cerebral oxidative injury. Curr. Aging Sci. 1(3), 169-174 (2008).

140. Kakkar V, Muppu SK, Chopra K, Kaur IP. Curcumin loaded solid lipid nanoparticles: an efficient formulation approach for cerebral ischemic reperfusion injury in rats. Eur. J. Pharm. Biopharm. 85(3 Pt A), 339-345 (2013).

141. Marushima A, Suzuki K, Nagasaki Y et al. Newly synthesized radical-containing nanoparticles enhance neuroprotection after cerebral ischemia-reperfusion injury. Neurosurgery 68(5), 1418-1425; discussion 1425-1416 (2011).

142. Reddy MK, Labhasetwar V. Nanoparticle-mediated delivery of superoxide dismutase to the brain: an effective strategy to reduce ischemia-reperfusion injury. FASEB J. 23(5), 1384-1395 (2009).

143. Yun X, Maximov VD, Yu J, Zhu H, Vertegel AA, Kindy MS. Nanoparticles for targeted delivery of antioxidant enzymes to the brain after cerebral ischemia and reperfusion injury. J. Cereb. Blood Flow Metab. 33(4), 583-592 (2013).

144. Celardo I, Pedersen JZ, Traversa E, Ghibelli L. Pharmacological potential of cerium oxide nanoparticles. Nanoscale 3(4), 1411-1420 (2011).

145. Estevez AY, Pritchard S, Harper K et al. Neuroprotective mechanisms of cerium oxide nanoparticles in a mouse hippocampal brain slice model of ischemia. Free Radic. Biol. Med. 51(6), 1155-1163 (2011).

146. Kim CK, Kim T, Choi IY et al. Ceria nanoparticles that can protect against ischemic stroke. Angew. Chem. Int. Ed. Engl. 51(44), 11039-11043 (2012).

-• Excellent research reveals protective effects of ceria NPs on ischemic stroke.

147. Yang DY, Wang MF, Chen IL, Chan YC, Lee MS, Cheng FC. Systemic administration of a water-soluble hexasulfonated C(60) (FC(4)S) reduces cerebral ischemia-induced infarct volume in gerbils. Neurosci. Lett. 311(2), 121-124 (2001).

148. Lin AM, Fang SF, Lin SZ, Chou CK, Luh TY, Ho LT. Local carboxyfullerene protects cortical infarction in rat brain. Neurosci. Res. 43(4), 317-321 (2002).

149. Zheng Z, Lee JE, Yenari MA. Stroke: molecular mechanisms and potential targets for treatment. Curr. Mol. Med. 3(4), 361-372 (2003).

150. Kim JY, Park J, Chang JY, Kim SH, Lee JE. Inflammation after ischemic stroke: the role of leukocytes and glial cells. Exp. Neurobiol. 25(5), 241-251 (2016).

151. Bernardi A, Frozza RL, Horn AP et al. Protective effects of indomethacin-loaded nanocapsules against oxygen-glucose deprivation in organotypic hippocampal slice cultures: involvement of neuroinflammation. Neurochem. Int. 57(6), 629-636 (2010).

152. Wang Q, Sun AY, Pardeike J, Muller RH, Simonyi A, Sun GY. Neuroprotective effects of a nanocrystal formulation of sPLA(2) inhibitor PX-18 in cerebral ischemia/reperfusion in gerbils. Brain Res. 1285, 188-195 (2009). 
153. Kim ID, Lim CM, Kim JB et al. Neuroprotection by biodegradable PAMAM ester (e-PAM-R)-mediated HMGB1 siRNA delivery in primary cortical cultures and in the postischemic brain. J. Control. Rel. 142(3), 422-430 (2010).

154. Broughton BR, Reutens DC, Sobey CG. Apoptotic mechanisms after cerebral ischemia. Stroke 40(5), e331-339 (2009).

155. Turley KR, Toledo-Pereyra LH, Kothari RU. Molecular mechanisms in the pathogenesis and treatment of acute ischemic stroke. J. Invest. Surg. 18(4), 207-218 (2005).

156. Karatas H, Aktas Y, Gursoy-Ozdemir Y et al. A nanomedicine transports a peptide caspase-3 inhibitor across the blood-brain barrier and provides neuroprotection. J. Neurosci. 29(44), 13761-13769 (2009).

157. Al-Jamal KT, Gherardini L, Bardi G et al. Functional motor recovery from brain ischemic insult by carbon nanotube-mediated siRNA silencing. Proc. Natl Acad. Sci. USA 108(27), 10952-10957 (2011).

158. Cai W, Chen X. Nanoplatforms for targeted molecular imaging in living subjects. Small 3(11), 1840-1854 (2007).

159. Flogel U, Ding Z, Hardung $\mathrm{H}$ et al. In vivo monitoring of inflammation after cardiac and cerebral ischemia by fluorine magnetic resonance imaging. Circulation 118(2), 140-148 (2008).

160. Lin KY, Kwong GA, Warren AD, Wood DK, Bhatia SN. Nanoparticles that sense thrombin activity as synthetic urinary biomarkers of thrombosis. ACS Nano 7(10), 9001-9009 (2013).

161. Lepousez G, Nissant A, Lledo PM. Adult neurogenesis and the future of the rejuvenating brain circuits. Neuron 86(2), 387-401 (2015).

162. Braun SM, Jessberger S. Adult neurogenesis: mechanisms and functional significance. Development 141(10), 1983-1986 (2014).

163. Thompson A, Boekhoorn K, Van Dam AM, Lucassen PJ. Changes in adult neurogenesis in neurodegenerative diseases: cause or consequence? Genes Brain Behav. 7(Suppl. 1) 28-42 (2008).

164. Winner B, Kohl Z, Gage FH. Neurodegenerative disease and adult neurogenesis. Eur. J. Neurosci. 33(6), 1139-1151 (2011).

165. Gallarda BW, Lledo PM. Adult neurogenesis in the olfactory system and neurodegenerative disease. Curr. Mol. Med. 12(10), 1253-1260 (2012).

166. Gincberg G, Arien-Zakay H, Lazarovici P, Lelkes PI. Neural stem cells: therapeutic potential for neurodegenerative diseases. Br. Med. Bull. 104, 7-19 (2012).

167. Curtis MA, Connor B, Faull RL. Neurogenesis in the diseased adult human brain-new therapeutic strategies for neurodegenerative diseases. Cell Cycle 2(5), 428-430 (2003).

168. Wang Y, Cooke MJ, Sachewsky N, Morshead CM, Shoichet MS. Bioengineered sequential growth factor delivery stimulates brain tissue regeneration after stroke. J. Control. Rel. 172(1), 1-11 (2013).

169. Arya A, Gangwar A, Singh SK et al. Cerium oxide nanoparticles promote neurogenesis and abrogate hypoxia-induced memory impairment through AMPK-PKC-CBP signaling cascade. Int. J. Nanomedicine 11, 1159-1173 (2016).

170. Estevez AY, Erlichman JS. The potential of cerium oxide nanoparticles (nanoceria) for neurodegenerative disease therapy. Nanomedicine (Lond.) 9(10), 1437-1440 (2014).

171. Katoh M. WNT signaling in stem cell biology and regenerative medicine. Curr. Drug Targets 9(7), 565-570 (2008).

172. Lie DC, Colamarino SA, Song HJ et al. Wnt signalling regulates adult hippocampal neurogenesis. Nature 437(7063), 1370-1375 (2005).

173. Inestrosa NC, Arenas E. Emerging roles of Wnts in the adult nervous system. Nat. Rev. Neurosci. 11(2), 77-86 (2010).

174. Frame S, Cohen P. GSK3 takes centre stage more than 20 years after its discovery. Biochem. J. 359(Pt 1), 1-16 (2001).

175. Shah DA, Kwon SJ, Bale SS, Banerjee A, Dordick JS, Kane RS. Regulation of stem cell signaling by nanoparticle-mediated intracellular protein delivery. Biomaterials 32(12), 3210-3219 (2011).

176. Tiwari SK, Agarwal S, Seth B et al. Curcumin-loaded nanoparticles potently induce adult neurogenesis and reverse cognitive deficits in Alzheimer's disease model via canonical Wnt/beta-catenin pathway. ACS Nano 8(1), 76-103 (2014).

177. Leong SY, Turnley AM. Regulation of adult neural precursor cell migration. Neurochem. Int. 59(3), 382-393 (2011).

178. Li X, Liu X, Zhao W, Wen X, Zhang N. Manipulating neural-stem-cell mobilization and migration in vitro. Acta Biomater. 8(6), 2087-2095 (2012).

179. Gelain F, Cigognini D, Caprini A et al. New bioactive motifs and their use in functionalized self-assembling peptides for NSC differentiation and neural tissue engineering. Nanoscale 4(9), 2946-2957 (2012).

180. Brown RE, Stevens DR, Haas HL. The physiology of brain histamine. Prog. Neurobiol. 63(6), 637-672 (2001).

181. Bernardino L, Eiriz MF, Santos T et al. Histamine stimulates neurogenesis in the rodent subventricular zone. Stem Cells 30(4), 773-784 (2012).

182. Maden M. Retinoic acid in the development, regeneration and maintenance of the nervous system. Nat. Rev. Neurosci. 8(10), 755-765 (2007).

183. Maia J, Santos T, Aday $S$ et al. Controlling the neuronal differentiation of stem cells by the intracellular delivery of retinoic acid-loaded nanoparticles. ACS Nano 5(1), 97-106 (2011). 
184. Santos T, Ferreira R, Maia Jet al. Polymeric nanoparticles to control the differentiationof neural stem cells in the subventricular zone oxide nanoparticles on PC12 neuronal-like cells: proliferation, differentiation, and dopamine secretion of the brain. ACS Nano 6(12), 10463-10474 (2012).

185. Ciofani G, Genchi GG, Liakos Iet al. Effects of cerium oxide cells in the subventricular zone of the brain nanoparticles on PC12neuronal-like cells: proliferation, differentiation, and dopamine secretion. Pharm Res 30(8), 2133-2145 (2013).

186. Steiner B, Wolf S, Kempermann G. Adult neurogenesis and neurodegenerative disease. Regen. Med. 1(1), 15-28 (2006).

187. Srikanth M, Kessler JA. Nanotechnology-novel therapeutics for CNS disorders. Nat. Rev. Neurol. 8(6), 307-318 (2012).

188. Chhabra R, Tosi G, Grabrucker AM. Emerging use of nanotechnology in the treatment of neurological disorders. Curr. Pharm. Des. 21(22), 3111-3130 (2015).

189. Lammers T, Aime S, Hennink WE, Storm G, Kiessling F. Theranostic nanomedicine. Acc. Chem. Res. 44(10), 1029-1038 (2011).

190. Vega-Villa KR, Takemoto JK, Yanez JA, Remsberg CM, Forrest ML, Davies NM. Clinical toxicities of nanocarrier systems. Adv. Drug Deliv. Rev. 60(8), 929-938 (2008).

191. Sharifi S, Behzadi S, Laurent S, Forrest ML, Stroeve P, Mahmoudi M. Toxicity of nanomaterials. Chem. Soc. Rev. 41(6), 2323-2343 (2012).

-• Excellent review on NPs toxicology and methodologies for evaluating NPs toxicity. 
(

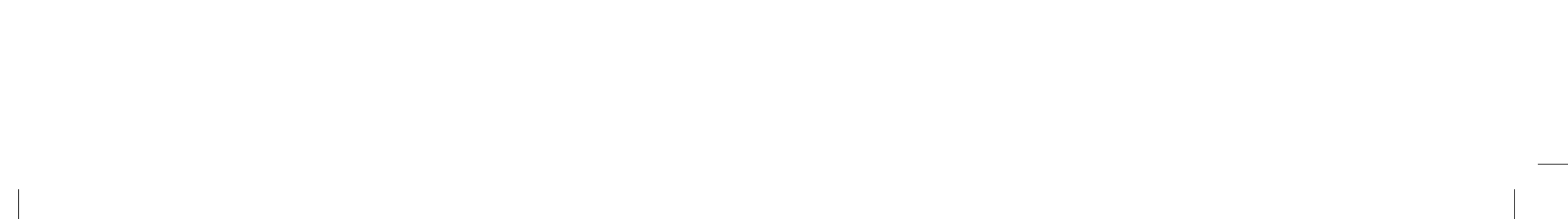

